\title{
Impactos do ADTEN e do FNDCT sobre o Desempenho e os Esforços Tecnológicos das Firmas Industriais Brasileiras
}

Fernanda De Negri

Instituto de Pesquisa Econômica Aplicada

João Alberto De Negri

Instituto de Pesquisa Econômica Aplicada

Mauro Borges Lemos

CEDEPLAR-Universidade Federal de Minas Gerais

\section{Resumo}

O objetivo deste trabalho é avaliar o impacto do Programa de Apoio ao Desenvolvimento Tecnológico da Empresa Nacional (ADTEN) o do Fundo Nacional para o Desenvolvimento Científico e Tecnológico (FNDCT), administrado pela FINEP, sobre o desempenho econômico e tecnológico das empresas beneficiadas. O trabalho mostrou que os programas têm alcance relativamente pequeno para as dimensōes da indústria brasileira. O programa atende menos de $0,1 \%$ das firmas industriais brasileiras com mais de dez pessoas ocupadas e o volume de recursos que são emprestados para as empresas no âmbito dos programas representam menos de $3 \%$ dos gastos realizados pelas próprias empresas em $\mathrm{P} \& \mathrm{D}$ no ano de 2000 e 2003. No período de 1996 a 2003, foram encontradas evidências robustas de que os programas influenciam positivamente os gastos privados de $\mathrm{P} \& \mathrm{D}$ das empresas, sugerindo a inexistência do chamado efeito crowding out. E há evidências também robustas de que os programas influenciam positivamente o crescimento das empresas.

Palavras-Chave | Firmas; Inovação Tecnológica; Política Tecnológica; Produtividade Código JEL | L25 


\section{Abstract}

The present study, which assesses the impact of the National Technological Development Support Program (ADTEN) and Scientific and Technological Development Fund (FNDCT), sponsored by the Research \& Projects Financing Agency (FINEP), on the technical performance and strength of Brazilian industrial firms, is unprecedented in its content and method. It shows that this $R \& D$ incentive programs reaches a relatively limited number of firms, considering the magnitude of the Brazilian industrial sector. The program reaches less than $0,1 \%$ of Brazilian industrial firms with over ten employees, and the volume of resources that firms borrowed within the program's framework was less than $3 \%$ of their R\&D expenditures in 2000 and 2003. It was found evidences that Programs had a positive influence on companies' private R\&D expenditures from 1996 to 2003. One can say that at least the crowding out hypothesis can be rejected. There are also strong evidences that the program has positively influenced the growth of firms.

Keywords | Firms; Technological Innovation; Technological Policy; Productivity

JEL-CODE | L25

\section{Introdução}

A indústria brasileira possui taxas de inovação e gastos com pesquisa e desenvolvimento (P\&D) bastante inferiores aos observados nos países desenvolvidos. Entre os principais obstáculos à inovação tecnológica no Brasil, ${ }^{1}$ estão os elevados custos e riscos associados aos projetos de inovação, aliados à escassez de fontes de financiamento adequadas para esses projetos. Assim, programas de financiamento à inovação e ao desenvolvimento científico e tecnológico podem, pelo menos potencialmente, ampliar significativamente o esforço tecnológico e, consequentemente, a taxa de inovação no país.

Este trabalho procura contribuir no debate sobre a efetividade de mecanismos públicos de financiamento às atividades tecnológicas como elemento indutor do esforço tecnológico do setor privado. Particularmente, busca-se avaliar o impacto de

1 Os dados da PINTEC apontam os três principais obstáculos, segundo as firmas, para a realização de inovações tecnológicas. São eles, nesta ordem: 1) risco econômico dos projetos, 2) elevados custos e 3) escassez de fontes de financiamento. 
dois programas, administrados pela Financiadora de Estudos e Projetos (FINEP): o Programa de Apoio ao Desenvolvimento Tecnológico da Empresa Nacional (ADTEN) e o Fundo Nacional para o Desenvolvimento Científico e Tecnológico (FNDCT), por meio da linha chamada de "FNDCT cooperativo".

Os autores deste trabalho desconhecem a existência de trabalhos publicados que procuram avaliar a eficácia do ADTEN, do FNDCT ou de outro programa similar no desempenho e nos gastos em pesquisa e desenvolvimento (P\&D) das empresas. É justamente sobre esse tema que se debruça esse esforço de pesquisa. Mais especificamente procura-se responder às seguintes perguntas:

1) Existe substituição ou complementaridade entre os fundos públicos provenientes desses programas e os recursos privados aplicados em $\mathrm{P} \& \mathrm{D}$ ? Ou seja, procurase saber se a existência desses programas alavanca ou desloca os investimentos privados em $\mathrm{P} \& \mathrm{D}$, efeitos esses chamados na literatura internacional de efeitos additionality e crowding out.

2) Os beneficiários dos programas avaliados possuem desempenho econômico superior aos não beneficiários? A resposta a essa pergunta será dada comparando a produtividade e o crescimento das firmas beneficiadas vis-à-vis às não-beneficiadas.

A próxima seção faz uma discussão sobre as questões metodológicas relativas à avaliação de políticas públicas, sobre os métodos econométricos e as informações que serão empregadas. Na seção 3 é feita uma breve descrição dos programas avaliados e do seu alcance. Os resultados da avaliação econométrica são apresentados na seção 5, enquanto a última seção sintetiza os resultados e apresenta as principais conclusōes.

\section{Avaliação de programas tecnológicos: questões metodológicas}

Para realizar este trabalho, utilizamos uma base de dados organizada pelo Instituto de Pesquisa Econômica Aplicada (IPEA) ${ }^{2}$ de diversas fontes. ${ }^{3}$ As principais bases de informação utilizadas para este trabalho são a Pesquisa Industrial Anual (PIA) e a Pesquisa Industrial de Inovação Tecnológica (PINTEC). A PIA contém informações

2 Detalhes sobre a construção da base de dados, ver em De Negri (2003).

3 O IPEA não tem a posse física das informações utilizadas neste trabalho e, portanto, a realização de trabalhos como este só é possível devido às parcerias estabelecidas entre o IPEA, O IBGE, O MTE, o BACEN, O MPO, a SECEX-MDIC e a FINEP. O acesso às informações necessárias ao trabalho seguiu rigorosamente os procedimentos que garantem o sigilo de informações restritas. 
detalhadas sobre o conjunto de receitas e custos das empresas industriais brasileiras, bem como o seu setor de atividade, desde 1996 até $2003 .{ }^{4}$ A PINTEC, por sua vez, segue o padrão do Manual de Oslo ${ }^{5}$ e contém informações sobre as atividades inovativas e os esforços tecnológicos das firmas industriais.

A essas duas bases de dados foram adicionadas, a partir do código de identificação de cada empresa, informações provenientes de outras fontes. A Relação Anual de Informaçôes Sociais (RAIS) trouxe informações sobre as características do pessoal ocupado nas empresas, tais como idade, escolaridade média, tempo de emprego, remuneração e ocupação. Esse registro é anual e também cobre o período de 1996 a 2003. Esse conjunto de informaçōes é capaz de fornecer um retrato bastante completo das empresas industriais brasileiras. A base da SECEX, por sua vez, contém o valor das operações de comércio exterior de cada uma delas.

Dessa forma, o banco de dados que foi utilizado é composto por uma amostra de aproximadamente 80 mil firmas industriais com mais de 10 pessoas ocupadas e por 5 milhões de trabalhadores que nelas trabalham. Essas firmas são responsáveis por aproximadamente $95 \%$ do valor adicionado na indústria brasileira. O período analisado compreende 8 anos: 1996-2003. Com a colaboração da FINEP, foi possível identificar as empresas beneficiárias do ADTEN no período 1997-2005 e do FNDCT no período 1999-2005.

\subsection{Abordagem econométrica}

No que diz respeito à avaliação de políticas públicas de um modo geral, os métodos quantitativos procuram avaliar se o desempenho dos beneficiários ou participantes da política é melhor do que seria na ausência de incentivos públicos. A fim de medir o impacto desses programas, o avaliador deveria saber o que teria acontecido com os beneficiários, caso não tivessem tido acesso ao programa. A questão é que o avaliador pode observar apenas o desempenho dos não-beneficiários vis-à-vis ao desempenho dos beneficiários. Entretanto, o desempenho dos beneficiários, caso não tivessem tido acesso ao programa, é uma variável não-observada pelo avaliador, assim como não é observado o desempenho dos não-beneficiários, caso tivessem tido acesso ao programa.

O tratamento a que uma parcela das firmas está submetida é, portanto, a participação no programa tecnológico (ou na política pública). Formalmente, podemos

4 No momento em que este trabalho foi concluído.

5 E, portanto, é comparável internacionalmente com outras pesquisas do gênero, como a Community Innovation Survey (CIS3) dos países da União Europeia. 
chamar de $Y_{i 1}$ a variável de resultado (desempenho econômico e ou tecnológico, por exemplo) com o tratamento e $Y_{i 0}$ o resultado sem o tratamento. Não é possível que os indivíduos avaliados pertençam aos dois grupos simultaneamente, portanto, não é possível observar ambos os resultados $Y_{i 0}$ e $Y_{i 1}$ para um mesmo indivíduo $i$. Em virtude disso, o problema com o qual nos deparamos na avaliação está relacionado à falta de informações (Wooldridge, 2002). Assim, a principal questão metodológica consiste em construir um contra factual de política ou um grupo de controle adequado para se avaliar o impacto do programa (Klette et al., 2000; Arvanitis, 2002).

Segundo Arvanitis (2002), "since neither the firms receiving support, nor those not applying for government-sponsored projects can be considered random draws, the construction of a valid control group is a challenging task to be performed by the evaluator". A questão relevante é que, para analisar o impacto do programa por meio da comparação simples entre beneficiários e não-beneficiários, é preciso que ambos os grupos sejam extraídos aleatoriamente do universo das empresas.

Essa aleatoriedade do acesso aos programas tecnológicos não é plausível nem do ponto de vista das empresas que requerem o suporte público nem das agências responsáveis por conceder o financiamento. ${ }^{6}$ Da parte das empresas, é possível que apenas as mais aptas tecnologicamente ou mais dispostas a realizar esforços tecnológicos busquem o suporte governamental para realizar projetos tecnológicos. Da parte das agências financiadoras, é possível que existam uma série de requisitos prévios para que as empresas façam parte do programa.

Segundo Blundell e Costa Dias (2000), "an individual's participation decision is probably based on personal characteristics that may well affect the outcome $Y$ as well”. Se isso é verdade, deve existir alguma correlação entre a variável de participação na política $(P)$ e o termo de erro. Em síntese, a variável $P_{i}$, que identifica os participantes e não-participantes da política não é uma variável aleatória, contrariando um dos pressupostos básicos de modelo de mínimos quadrados. Por essas razóes, esse modelo gera estimativas viesadas dos parâmetros da equação (Hussinger, 2003).

Busom (2000) acrescenta mais um problema que, de certa forma, está bastante correlacionado com o viés de seleção: o problema da endogeneidade do financiamento público. Esse problema decorre do fato de que a decisão de conceder o financiamento por parte das agências responsáveis pode estar baseada em indicadores de desempenho das firmas, que, possivelmente, sejam os próprios indicadores de

6 Busom (2000) faz uma discussão sobre os fatores determinantes da decisão das empresas em buscar suporte público, bem como da decisão das agências financiadoras em conceder o financiamento. 
desempenho a serem posteriormente avaliados para estimar a eficácia dos programas. Assim o financiamento seria concedido prioritariamente, por exemplo, para firmas mais produtivas, o que dificultaria a avaliação posterior do impacto do financiamento sobre a produtividade delas. Dessa forma, mais uma vez, teríamos uma correlação entre a variável $P_{i}$ e o termo de erro em virtude da não-aleatoriedade da participação na política.

A seguir apresentamos os métodos mais frequentemente utilizados para corrigir os problemas relativos à avaliação de políticas públicas e que serão os métodos empregados neste trabalho.

\subsection{Propensity Score Matching}

Um método comumente utilizado para análises do impacto de políticas públicas é o Propensity Score Matching (PSM). Os experimentos quase naturais utilizam geralmente essa técnica que também é largamente utilizada para avaliação de programas sociais. Meyer (1995) tem uma boa descrição dos procedimentos para experimentos quase naturais em economia e Wooldrigde (2002), sobre o efeito médio do tratamento.

A técnica de PSM consiste na estimação de um modelo probabilístico (equação 1), que procura corrigir o fato que a distribuição do grupo de tratamento não é aleatória, criando grupos de controle a partir da probabilidade de a firma ter recebido o tratamento. ${ }^{7}$ Formalmente:

$$
P_{i}=\gamma Z_{i}+\varepsilon_{i}
$$

onde $P_{i}$ é a variável observada que diz se a firma participa ou não do programa de financiamento e $Z_{i}$ é um vetor de variáveis explicativas relevantes.

Assim, o PSM faz a correspondência (matching) entre os indivíduos segundo as probabilidades estimadas para cada um deles. Essa correspondência considera dois tipos de indivíduos: os que receberam e os que não receberam o tratamento.

7 Busom (2000) aponta alguns fatores determinantes do acesso a programas de financiamento de P\&D, tais como tamanho da firma, origem de capital, desempenho externo e tecnológico, entre outros. No que diz respeito aos fatores determinantes da decisão da agência financiadora em conceder ou não o financiamento, estes dependem fortemente das características específicas de cada programa. Eles podem ser o setor de atuação das firmas, a existência de maiores ou menores externalidades positivas derivadas do investimento em determinado projeto, o tamanho da firma etc. 
Considere $i$ o indivíduo que recebeu o tratamento e $\hat{p}\left(X_{i}\right)$ a sua probabilidade de receber o tratamento. Considere $j$ o indivíduo que não recebeu o tratamento e $\hat{p}\left(X_{j}\right)$ a sua probabilidade de receber o tratamento. Se dentro de um pequeno raio partindo de $\hat{p}\left(X_{i}\right)$ existir pelo menos um $\hat{p}\left(X_{j}\right)$, $i$ e $j$ formarão um par de indivíduos tratamento-controle. Esses grupos podem ser acompanhados ao longo do tempo de forma a quantificar os efeitos do tratamento. Formalmente temos:

$$
\Phi\left(X_{j} \beta\right) \approx \Phi\left(X_{i} \beta\right) \Rightarrow X_{j} \beta \approx X_{i} \beta \Rightarrow \sum_{k=1}^{q} \beta_{k}\left(x_{j k}-x_{i k}\right) \approx 0,
$$

onde:

$$
\begin{aligned}
& \hat{p}\left(X_{j}\right)=\Phi\left(X_{j} \beta\right) \\
& \Phi(\cdot)=\text { Função de distribuição acumulada; }
\end{aligned}
$$

$X=$ Vetor dos determinantes da probabilidade da firma ser parte do grupo de tratamento;

$\beta=$ Parâmetros do modelo probabilístico.

O primeiro procedimento utilizado neste trabalho consistiu, portanto, em encontrar um grupo de controle via Propensity Score Matching adaptando os procedimentos descritos em Aerts e Czarnitzki (2004). O procedimento pode ser detalhado em alguns passos:

1) Estabelecer e estimar um modelo probabilístico para obter a probabilidade estimada de a firma ser ou não beneficiária do programa no período de abrangência dele.

As variáveis explicativas utilizadas nos modelos probabilísticos serão:

- O tamanho da firma, medido pelo logaritmo natural do número de trabalhadores (pessoal ocupado).

- Dado que o grau de endividamento das firmas é um dos critérios de avaliação utilizados pela FINEP para selecionar os beneficiários, utilizou-se uma variável que mede o gasto com juros como proporção do faturamento das empresas. 
A partir dessa variável, as firmas foram agrupadas nos cinco quintis da relação de gastos com juros/faturamento. Assim, utilizaram-se quatro dummies (CR1 A CR4) representativas do quintil ocupado pela firma como variáveis explicativas no modelo.

- Logaritmo natural da idade da firma.

- O market share da firma no seu setor de atuação.

- Dummy para empresas estrangeiras.

- Dummy para firmas exportadoras defasada.

- Dummy para empresas que realizam atividades contínuas de P\&D. ${ }^{8}$

- Dummies para setores intensivos em tecnologia. ${ }^{9}$

- Dummies para empresas da região Sul/Sudeste.

2) A partir das probabilidades estimadas, calcular a distância de Mahalanobis entre cada uma das firmas beneficiárias e todas as demais não-beneficiárias.

3) Escolher, para cada firma beneficiária, a firma não-beneficiária mais próxima, de modo a obter o melhor grupo de controle possível.

4) Os passos anteriores foram feitos para a amostra total das firmas industriais e para outras duas subamostras: das firmas industriais inovadoras e das firmas industriais com gastos em $\mathrm{P} \& \mathrm{D} .{ }^{10}$

5) Assim, o conjunto das firmas beneficiárias teria três grupos de controle: um composto a partir da amostra completa, outro a partir da amostra de firmas inovadoras e um terceiro a partir da amostra de firmas com pedido de registros de patentes. Estes seriam os três contrafactuais utilizados no passo seguinte.

O próximo passo consiste em um teste de diferença de médias, que pode ser realizado de duas formas. A primeira delas consiste em verificar se existem diferenças significativas entre as empresas beneficiárias e as do grupo de controle no próprio ano que foi feito o procedimento de matching. As variáveis testadas, nesse caso, seriam a produtividade e os gastos em P\&D das empresas.

8 Quando utilizamos apenas informações da PIA para estimar o PROBIT, essa variável foi substituída por uma dummy para firmas com patentes em vigor no ano anterior ao da estimativa.

9 A classificação setorial de intensidade tecnológica foi baseada na classificação proposta pela OCDE.

10 Como veremos adiante, o número de beneficiárias é muito pequeno em comparação com o número total de empresas na amostra. Assim, o procedimento de estimar os modelos probabilísticos para sub-amostras destina-se a comparar grupos mais homogêneos de empresas beneficiárias e não beneficiárias. 
A segunda forma de se realizar o procedimento consiste no que se chama de "modelos de diferenças em diferenças". Nesse caso, o PROBIT seria estimado no período anterior ao período de tratamento e o teste de diferença de médias seria realizado no momento posterior ao este. Dessa forma, seria possível avaliar não os indicadores absolutos de produtividade e gastos em $\mathrm{P} \& \mathrm{D}$, mas sim suas taxas de crescimento. ${ }^{11}$ Basicamente, o método consiste em avaliar as mudanças no comportamento ou no desempenho médio dos indivíduos "tratados" antes e depois da política avaliada, e comparar essas mudanças com o grupo de controle.

Formalmente, o coeficiente que irá medir o impacto da política é dado por:

$$
\hat{\beta_{1}}=\left(\bar{Y}_{1 t}-\bar{Y}_{1 t-1}\right)-\left(\bar{Y}_{0 t}-\bar{Y}_{0 t-1}\right) \text {, }
$$

onde $\bar{Y}_{0 t-1}$ é a média amostral da variável resultado no primeiro ano para os nãobeneficiários, $\bar{Y}_{0 t}$ é a mesma média para os não-beneficiários (grupo de controle) no segundo ano. $\bar{Y}_{1 t-1}$ e $\bar{Y}_{1 t}$ são definidos de modo similar para o grupo de tratamento. Esse método nada mais faz além de expurgar os efeitos temporais causados por variáveis não-observáveis. Esse método contornaria o problema da inexistência de informações sobre os beneficiários, caso eles não tivessem não-recebido o tratamento.

Uma das desvantagens do método é que ele adota duas hipóteses importantes, e até certo ponto restritivas:

1) de que os efeitos temporais são os mesmos para os dois grupos (tratados e não-tratados);

2) de que não há mudanças na composição dos dois grupos.

\subsection{Modelos de seleção em dois estágios}

Esse tipo de modelo, inspirado em Heckman (1979) é mais adequado para dados em cortes transversais e consiste em estimar, num primeiro estágio, a probabilidade de a firma ser participante de determinado programa, ou seja, a equação de seleção. Num segundo estágio, a equação de resultado seria estimada, por mínimos quadrados, com a devida correção para o viés de seleção.

Formalmente, o primeiro estágio estimaria, por meio de um modelo PROBIT, a equação 1, que é a mesma utilizada no PSM. A partir dessa equação, podem ser obtidas estimativas da razão inversa de Mills para cada indivíduo da amostra, dada por:

11 Apenas com esse método será possível analisar o impacto dos programas sobre o crescimento das firmas beneficiárias, dado que o método é mais indicado ao tratamento de dados longitudinais. Os gastos em P\&D, entretanto, não puderam ser avaliados com essa metodologia devido à pequena intersecção existente entre as duas pesquisas de inovação. 


$$
\begin{aligned}
& \lambda_{i 1}\left(\bar{Z}_{i \gamma}\right)=\frac{\phi\left(\bar{Z}_{i} \gamma\right)}{\Phi\left(\bar{Z}_{i} \gamma\right)} \text { para as firmas participantes do programa e } \\
& \lambda_{i 0}\left(\bar{Z}_{i \gamma}\right)=-\frac{\phi\left(\bar{Z}_{i \gamma} \gamma\right)}{1-\Phi\left(\bar{Z}_{i \gamma}\right)} \text { para as firmas não-participantes, }
\end{aligned}
$$

onde $\phi($.$) e \Phi($.$) são as funções de densidade e de distribuição de probabilidade$ respectivamente.

A razão inversa de Mills é utilizada como instrumento para corrigir o viés de seleção no segundo estágio, que consiste em estimar a equação objetivo (6 e 7) por meio de mínimos quadrados (OLS), para a amostra completa e para o grupo dos participantes e dos não-participantes separadamente (Jarmin, 1998; Busom, 2000). As equações a serem estimadas são:

$$
\begin{aligned}
& Y_{i k}=\alpha_{k}+\beta_{k} X_{i k}+\lambda_{i k}\left(Z_{i} \gamma\right)+\mu_{i k} \\
& Y_{i k}=\alpha_{k}+\delta_{i k} P_{i k}+\beta_{k} X_{i k}+\lambda_{i k}\left(Z_{i} \gamma\right)+\mu_{i k}
\end{aligned}
$$

A equação 6 é a equação de tratamento a ser estimada para cada grupo (beneficiárias e não-beneficiárias) separadamente. A equação 7 , por sua vez, é a equação de tratamento a ser estimada para a amostra completa. Em ambas $\mathrm{k}=0$ para as não-participantes, e $\mathrm{k}=1$ para as firmas que participam do programa, $X_{i k}$ é um vetor de variáveis explicativas, $\lambda_{i k}\left(\bar{Z}_{i \gamma}\right)$ é a razão inversa de Mills e $P_{i k}$ é a variável binária para firmas que participam do programa.

A existência do viés de seleção pode, então, ser corrigida e testada a partir da significância estatística do termo $\lambda$ nas equaçóes 6 e 7 . Depois de estimar as equações de tratamento, é necessário, ainda, calcular o Efeito Médio do Tratamento (ATE), o que pode ser feito de duas maneiras.

Uma das formas é encontrada em Busom (2000). O autor procura avaliar o efeito de subsídio à $\mathrm{P} \& \mathrm{D}$ sobre o esforço próprio de $\mathrm{P} \& \mathrm{D}$ das firmas beneficiárias, a fim de estimar os efeitos de adição e crowding out. Após estimar a equação 6 para os dois grupos de firmas (participantes e não-participantes da política de incentivo) separadamente, utilizando como variável dependente os gastos em $\mathrm{P} \& \mathrm{D}$ das firmas, o autor compara os gastos previstos das firmas participantes ( $\left.Y_{1}^{\text {predict }}=E\left\{Y_{1} \mid P=1\right\}\right)$ com seus gastos potenciais, que são os gastos previstos utilizando os coeficientes estimados para as não-participantes ( $\left.Y_{1}^{\text {potential }}=E\left\{Y_{0} \mid P=1\right\}\right)$. O $Y_{1}^{\text {potential }}$ constitui o 
contrafactual de política necessário e a comparação com os gastos previstos mediria o impacto da política sobre os esforços próprios de P\&D das firmas. Formalmente, o efeito do tratamento segundo essa primeira metodologia (ATE1) seria dado por:

$$
\begin{aligned}
& A T E 1=Y_{1}^{\text {predict }}-Y_{1}^{\text {potential }}=E\left\{Y_{1} \mid P=1\right\}-E\left\{Y_{1} \mid P=0\right\} \text { ou } \\
& A T E 1=\bar{X}_{1} \beta_{1}-\bar{X}_{1} \beta_{0},
\end{aligned}
$$

onde $\beta_{1}$ é o vetor de coeficientes estimados para as firmas participantes do programa, $\beta_{0}$ representa os coeficientes estimados para as firmas não-participantes e $X_{1}$ são os regressores das firmas participantes. ${ }^{12} \mathrm{O}$ efeito do tratamento, nessa abordagem, é calculado apenas para as firmas participantes, ou seja, ele é o "Average Treatment Effects on treated".

Outra forma de calcular o efeito médio do tratamento (ATE2) consiste em estimar o segundo estágio para a amostra completa das firmas (participantes e nãoparticipantes conjuntamente) a partir da equação 7. Nessa equação, haverá uma variável binária identificando os participantes do programa. $\mathrm{O}$ efeito médio do tratamento pode ser calculado, segundo Greene (2000, p. 933) como:

$$
\begin{aligned}
& A T E 2=E\left\{Y_{1} \mid P=1\right\}-E\left\{Y_{1} \mid P=0\right\} \quad \text { ou, nesse caso, } \\
& A T E 2=\left[\beta_{i} \bar{X}_{i}+\delta+\varphi\left(\frac{\phi\left(\bar{Z}_{i} \gamma\right)}{\Phi\left(\bar{Z}_{i} \gamma\right)}\right)\right]-\left[\beta_{i} \bar{X}_{i}+\varphi\left(-\frac{\phi\left(\bar{Z}_{i} \gamma\right)}{1-\Phi\left(\bar{Z}_{i} \gamma\right)}\right)\right] \\
& \text { ATE2 }=\delta+\varphi\left[\frac{\phi_{i}}{\Phi_{i}\left(1-\Phi_{i}\right)}\right],
\end{aligned}
$$

onde $\delta$ é o parâmetro estimado para a dummy relativa à participação no programa $\left(P_{i}\right), \varphi$ é o parâmetro estimado para o termo lambda (razão inversa de Mills) e os termos

$$
\left(\frac{\phi\left(\bar{Z}_{i} \gamma\right)}{\Phi\left(\bar{Z}_{i} \gamma\right)}\right) \text { e }\left(-\frac{\phi\left(\bar{Z}_{i} \gamma\right)}{1-\Phi\left(\bar{Z}_{i} \gamma\right)}\right)
$$

são a razão inversa de Mills para os participantes e não-participantes respectivamente. 
Uma das principais vantagens desse método, para corrigir o viés de seleção, é o fato de que ele pode ser aplicado em dados transversais (cross section). Além disso, pode-se demonstrar que o procedimento produz estimativas assintoticamente consistentes e não-viesadas dos parâmetros da regressão. Em geral pode haver uma boa sobreposição entre as variáveis do PROBIT e da regressão, e o modelo continuará identificado, desde que os resíduos sejam normais e o modelo correto.

Entretanto, se o vetor $X$ (equaçōes 6 e 7 ) for igual ao vetor $Z$ (equação 1), pode existir uma elevada correlação entre as razões inversas de Mills $\left(\lambda_{i k}\left(\bar{Z}_{i} \gamma\right)\right)$ e $\beta_{k} \bar{X}_{i k}$, o que pode fazer com que as estimativas dos parâmetros possuam desvios-padrão muito elevados (Hussinger, 2003).

\section{Os programas avaliados e seu alcance}

\subsection{O FNDCT cooperativo}

O FNDCT tem sido uma das principais fontes de recursos para o financiamento de atividades científicas e tecnológicas no país. O fundo foi criado no final da década de 1960 e foi um instrumento poderoso para impulsionar o desenvolvimento científico e tecnológico do Brasil principalmente a partir de 1971, quando a Financiadora de Estudos e Projetos (FINEP) passou a ocupar a sua secretaria executiva.

Tradicionalmente, os principais beneficiários dos recursos do FNDCT foram as universidades e instituições de ensino e pesquisa, enquanto o financiamento às empresas sempre foi provido pela FINEP com fontes próprias (Bastos, 2003). Essa negligência à participação do setor produtivo comumente foi alvo de críticas à política de financiamento à $\mathrm{C} \& \mathrm{~T}$ no Brasil. Além dessa, outras críticas estavam relacionadas à instabilidade e à descontinuidade dos fluxos de recursos efetivamente alocados ao fundo, que era muito dependente de fontes orçamentárias.

Os fundos setoriais ${ }^{13}$ foram criados na tentativa de minorar esses problemas. Sua criação, em 1999, marcou uma mudança nos tradicionais mecanismos de financiamento ao estimular a interação entre as empresas e universidades e centros de pesquisa. Apesar disso, o arcabouço legal brasileiro não permitia, pelo menos até a Lei de Inovação em 2005, a subvenção à empresas privadas, mesmo em atividades de CT\&I. Segundo Pereira (2002), isso explica por que a intermediação entre fontes públicas e empresas privadas sempre ficou a cargo de universidades e centros de pesquisa. 
Dessa forma, os fundos setoriais preveem a participação de empresas privadas, especialmente por meio dos chamados projetos cooperativos. Neles, empresas públicas e privadas se poderiam associar a projetos de pesquisa executados por universidades e instituições de pesquisa públicas ou privadas, sem fins lucrativos. Estas últimas seriam os intermediários entre o setor produtivo e a FINEP e também os executores dos projetos financiados pelo chamado FNDCT cooperativo, visando desenvolver novos produtos e processos de interesse do setor produtivo. As empresas, por sua vez, seriam responsáveis pela contrapartida técnica e financeira ao projeto, contrapartida essa que comumente fica muito próxima do valor financiado pela FINEP. A principal fonte de recursos para os projetos cooperativos é o Fundo Verde Amarelo.

Desde a criação dos fundos setoriais, já foram repassados recursos da ordem de mais de $\mathrm{R}$ \$ 2,3 bilhões, em caráter não-reembolsável, para financiar projetos de pesquisa em universidade e centros de pesquisa sem fins lucrativos, com ou sem a participação de empresas (Tabela 1). A despeito de raras exceções, ainda não foi feita uma avaliação de qual o montante dos recursos dos fundos setoriais que é, efetivamente, aplicado em projetos de cooperação entre as universidades e o setor produtivo (os chamados projetos cooperativos). Pereira (2002) procurou avaliar a participação empresarial em três dos fundos setoriais, o CT-PETRO, o CT-FVA e o CT-ENERG. Suas conclusões apontam para um participação não-desprezível do setor privado nesses fundos, embora ainda muito pequena dado os objetivos deles.

Nos projetos cooperativos selecionados ${ }^{14}$ para essa avaliação, entre os anos de 2000 e outubro de 2005, 356 intervenientes (empresas públicas ou privadas e até órgãos públicos) se associaram a 168 instituições executoras (universidades e centros de pesquisa) em aproximadamente 693 operações de financiamento nãoreembolsáveis (Tabela 2). ${ }^{15}$ Nesses projetos, estiveram envolvidos 483 pesquisadores de universidades e centros de pesquisa.

A Tabela 2 também mostra o volume de recursos aportados pela FINEP para os projetos cooperativos selecionados: aproximadamente R \$ 256 milhões entre 2000 e 2005 (em valores correntes). Muito embora esse número não corresponda ao total de projetos cooperativos financiados pela FINEP, ele é um indício da baixa participação de projetos envolvendo o setor privado no total dos recursos desembolsados pelo

14 A FINEP, gentilmente, cedeu informações sobre os intervenientes e executores de uma amostra dos projetos financiados pelo FNDCT cooperativo no período. Entretanto, não é possível saber exatamente o quanto essa amostra representa do total dos projetos cooperativos.

15 O maior número de projetos financiados vis-à-vis o número de empresas intervenientes decorre do fato de que muitas das empresas beneficiadas pelo programa estão associadas a mais de uma instituição de pesquisa e/ou a mais de um projeto. O mesmo pode acontecer com os executores dos projetos (instituições de pesquisa). 
TABELA 1

Desembolsos do FNDCT entre 1999 e 2005

\begin{tabular}{cc}
\hline Ano & Valores correntes (R\$) \\
$1999^{a}$ & 37.240 .000 \\
2000 & 134.411 .665 \\
2001 & 315.993 .601 \\
2002 & 315.447 .090 \\
2003 & 564.261 .623 \\
2004 & 593.971 .911 \\
$2005^{b}$ & 403.119 .664 \\
\hline
\end{tabular}

Fonte: MCT, <http://www.mct.gov.br/fontes/fundos/Recursos/Recursos_Default.htm>. Acesso em 25/1/06.

${ }^{a}$ Em 1999, apenas o CT-PETRO estava em operação.

${ }^{\mathrm{b}}$ Valores até novembro.

FNDCT (ver Tabela 1). A despeito de a criação dos fundos setoriais ter possibilitado uma nova janela de participação do setor privado no financiamento à C\&T no Brasil, ainda assim ela é muito baixa. Os projetos cooperativos respondem algo em torno de $20 \%$ do total dos recursos do FNDCT no período 2000 a $2005 .{ }^{16}$

Para saber como são as empresas industriais que tiveram acesso ao FNDCT cooperativo, cruzamos as informações das bases de dados descritas anteriormente com as informaçôes fornecidas pela FINEP sobre as firmas intervenientes beneficiadas pelo programa. Ao proceder esse cruzamento, a amostra de beneficiários se reduziu para 70 firmas da indústria de transformação. ${ }^{17}$ Suas características, bem como as características das demais firmas da indústria de transformação e de dois subgrupos industriais - firmas inovadoras e firmas com gastos em P\&D - estão descritas na Tabela 3.

Uma das principais variáveis que será objeto de análise nas próximas seções é o esforço tecnológico das firmas. Percebe-se que, tanto em termos absolutos quanto

16 Também cabe ressaltar que, entre os intervenientes, não estão apenas empresas privadas ou apenas empresas do setor produtivo. Entre esses beneficiários se encontram também organizações não-governamentais; fundações públicas de pesquisa e desenvolvimento, vinculadas ou não a universidades públicas; além de órgãos públicos, tais como ministérios ou secretarias dos governos estaduais etc. Ou seja, a despeito do FNDCT cooperativo estimular as parcerias universidade-empresa, apenas uma parcela dos seus beneficiários constitue-se, efetivamente, de empresas envolvidas em atividades produtivas.

17 Essa redução da amostra já era esperada, especialmente em virtude dos procedimentos amostrais da PINTEC e do fato de essa pesquisa ser censitária apenas para firmas com mais de 500 funcionários. 


\section{TABELA 2}

Número de operações de financiamento, instituições e pesquisadores envolvidos e valor dos financiamentos do FNDCT - 2000 a 2005

\begin{tabular}{|c|c|c|c|c|c|c|}
\hline Ano & $\begin{array}{l}\text { Intervenientes } \\
\text { (empresas) }\end{array}$ & $\begin{array}{l}\text { Instituiçõos } \\
\text { de pesquisa } \\
\text { (executores) }\end{array}$ & $\begin{array}{c}\text { № de } \\
\text { pesquisadores }\end{array}$ & $\begin{array}{c}\text { № de } \\
\text { operações }\end{array}$ & $\begin{array}{l}\text { Desembolsos } \\
\text { FINEP (R\$) }\end{array}$ & $\begin{array}{c}\text { Contrapartidas } \\
\text { (R\$) }\end{array}$ \\
\hline 2000 & 19 & 29 & 67 & 77 & 28.790 .976 & 26.296 .737 \\
\hline 2001 & 11 & 24 & 46 & 61 & 36.636 .358 & 20.183 .446 \\
\hline 2002 & 140 & 73 & 131 & 183 & 46.468 .896 & 44.540 .208 \\
\hline 2003 & 32 & 25 & 33 & 41 & 15.589 .119 & 18.043 .038 \\
\hline 2004 & 157 & 97 & 220 & 277 & 103.045 .432 & 101.423 .073 \\
\hline 2005 & 39 & 34 & 39 & 54 & 25.419 .375 & 12.833 .494 \\
\hline Total & 356 & 168 & 483 & 693 & 255.950 .156 & 223.319 .996 \\
\hline
\end{tabular}

Fonte: FINEP.

relativos (como proporção da receita líquida de vendas), as firmas beneficiárias possuem um esforço tecnológico superior às não-beneficiárias. Essas empresas gastaram cada uma, em média, $\mathrm{R} \$ 23$ milhões em Pesquisa e Desenvolvimento no ano de 2000, o que representou aproximadamente $4 \%$ da sua receita líquida de vendas. Enquanto isso, a média da indústria de transformação brasileira é de gastos próximos a pouco mais de $\mathrm{R} \$ 50$ mil por firma, o que é equivalente a $0,6 \%$ de sua receita líquida de vendas.

Evidentemente, isso ainda não pode ser apontado como um indício de sucesso do programa no que diz respeito ao incentivo aos gastos privados em P\&D. É possível que haja um viés importante na seleção dos beneficiários do FNDCT, na medida em que firmas que já sejam inovadoras e que já possuam maior esforço tecnológico sejam as principais demandantes de programas de incentivo à P\&D. Nas próximas seções, procuraremos neutralizar o efeito desse potencial viés de seleção, a fim de avaliar quais os reais impactos do programa sobre o esforço tecnológico das firmas beneficiárias. 
TABELA 3

Características das firmas industriais beneficiárias e não-beneficiárias do FNDCT (médias por firma) - 2003

\begin{tabular}{|c|c|c|c|c|}
\hline \multirow{2}{*}{ Indicadores } & \multirow{2}{*}{$\begin{array}{l}\text { Beneficiárias } \\
\text { do ADTEN }\end{array}$} & \multicolumn{3}{|c|}{ Não-beneficiárias } \\
\hline & & Total & $\begin{array}{c}\text { Firmas } \\
\text { inovadoras }^{a}\end{array}$ & \begin{tabular}{|c} 
Firmas com \\
gastos em \\
P\&D
\end{tabular} \\
\hline Faturamento $(R \$ 1.000)$ & 2.206 .840 & 10.985 & 22.469 & 88.955 \\
\hline Produtividade do trabalho $(\mathrm{R} \$)$ & 156.230 & 25.214 & 30.553 & 56.246 \\
\hline Escolaridade média dos funcionários (anos de estudo) & 10,1 & 7,7 & 8,02 & 8,75 \\
\hline Estoque de solicitações de patentes & 5,83 & 0,08 & 0,15 & 0,6 \\
\hline Estoque de solicitações de patentes (por 100 funcionários) & 0,37 & 0,10 & 0,13 & 0,37 \\
\hline Participação de firmas estrangeiras (\%) & $12 \%$ & $2 \%$ & $3 \%$ & $10 \%$ \\
\hline Valor médio das exportações $(R \$ 1.000)$ & 515.649 & 1.792 & 4.021 & 17.058 \\
\hline Coeficiente de exportaçãoc & 16,9 & 17,1 & 15,9 & 12,2 \\
\hline Gastos em P\&Dd (R\$) & 23.310 .000 & 50.205 & 140.022 & 742.333 \\
\hline - como proporção do faturamento (\%) & 4,0 & 0,6 & 1,6 & 8,3 \\
\hline Gastos privados em P\&D $(\mathrm{R} \$)$ & 21.701 .195 & 48.116 & 134.195 & 711.443 \\
\hline - como proporção do faturamento (\%) & 3,8 & 0,6 & 1,6 & 8,2 \\
\hline Participação de recursos privados nos gastos em P\&D & $93 \%$ & $96 \%$ & $96 \%$ & $96 \%$ \\
\hline № amostra & 50 & 10.466 & 4.806 & 1.776 \\
\hline № população & 70 & 83.164 & 30.127 & 5.683 \\
\hline
\end{tabular}

Fonte: IBGE, Diretoria de Pesquisas, Coordenação de Indústria, Pesquisa Industrial de Inovação Tecnológica, 2000. Elaboração: IPEA-DISET a partir da transformação dos dados obtidos na fonte e com a incorporação de dados da PIA/IBGE, SECEX/MDIC, CBE/BACEN, CEB/BACEN, ComprasNet/MPOG RAIS/MTE e FINEP.

a Empresas inovadoras são aquelas que realizaram algum tipo de inovação entre 1998 e 2000 ou que, nesse período, possuíam projetos de inovação incompletos ou inacabados.

b Valor adicionado (valor da transformação industrial) por funcionário.

c Apenas para firmas exportadoras.

d Gastos em P\&D incluem aqueles realizados internamente na firma, bem como a aquisição externa de P\&D, e foi dividido entre recursos públicos e privados. 


\subsection{ADTEN}

O FNDCT contou com uma rápida expansão do volume de recursos no início da década de 1970 e a FINEP passou a estabelecer um modo diversificado de operar o fundo. Nesse contexto, foi criado o programa Apoio ao Desenvolvimento Tecnológico da Empresa Nacional (ADTEN). Valores significativos de recursos do FNDCT foram repassados para esse programa entre 1976 e 1978. Historicamente o funding do programa é o Tesouro Nacional, os retornos dos empréstimos anteriores, recursos de organismos multilaterais, principalmente o Banco Interamericano de Desenvolvimento (BID) e aportes do Fundo Nacional de Desenvolvimento. No final da década de 1970, os recursos repassados ao ADTEN representavam cerca de 30\% dos recursos totais do FNDCT $^{18}$ e em 1987, no auge dos desembolsos realizado pelo programa, foram emprestados cerca de U\$ 150 milhóes. ${ }^{19}$

Desde o início, o ADTEN deu prioridade aos projetos de engenharia, centros de pesquisa e desenvolvimento nas empresas, inovação de produtos e processos; comercialização, compra de tecnologia no Brasil ou no exterior e apoio à criação de processos de controle de qualidade. O programa opera com prazo de carência de até três anos, prazo de amortização de até sete anos, e a participação da FINEP é de até $80 \%$ do projeto. As garantias reais são definidas na operação. Atualmente não há subsídios vinculados aos empréstimos e os encargos financeiros são equivalentes aos encontrados no mercado. Sobre os empréstimos incide a taxa de juros de longo prazo (TJLP), que atualmente (jan. 2006) é de $9 \%$ a.a., mais spread médio de $5 \%$ a.a. e taxa de abertura de crédito de $1 \%$.

Na Tabela 4 são apresentados o volume de recursos desembolsados no âmbito do ADTEN e o número de firmas beneficiadas pelo programa no período de 1997 a 2005. Nesse período, 457 empresas diferentes ${ }^{20}$ se beneficiaram do programa em 506 operações de financiamento.

O alcance do programa no fomento de atividades inovativas fica claro quando comparado os desembolsos dele com apenas um tipo de gasto em atividades inovativas das empresas: os dispêndios em P\&D dentro das empresas. No ano de 2003, os desembolsos do ADTEN representaram algo em torno de $3 \%$ dos investimentos em $\mathrm{P} \& \mathrm{D}$ das firmas. De forma geral, considerando que a FINEP é uma das principais agências de financiamento à inovação tecnológica no Brasil e que possui capacidade

18 Guimarães (1993).

19 Naidin et al. (1977).

20 O número de operações é diferente do número de firmas, porque 49 empresas tiveram mais de um projeto financiado pelo ADTEN durante o período. 
TABELA 4

Número de operações de financiamento, de firmas beneficiadas e montante emprestado pelo ADTEN entre 1997 e 2005

\begin{tabular}{ccccc}
\hline Ano & № de empresas & № de operações & $\begin{array}{c}\text { Valor emprestado } \\
(\mathrm{R} \$)\end{array}$ & $\begin{array}{c}\text { Valor emprestado } \\
\text { (US\$) }\end{array}$ \\
1997 & 93 & 95 & 678.802 .183 & 629.686 .626 \\
1998 & 128 & 132 & 722.699 .975 & 622.748 .794 \\
1999 & 55 & 56 & 234.922 .505 & 129.455 .285 \\
2000 & 36 & 36 & 116.967 .498 & 63.909 .681 \\
2001 & 41 & 41 & 221.107 .544 & 94.072 .304 \\
2002 & 52 & 52 & 328.916 .005 & 112.596 .195 \\
2003 & 27 & 27 & 208.449 .234 & 67.715 .698 \\
2004 & 18 & 18 & 135.932 .395 & 46.458 .319 \\
2005 & 48 & 49 & 573.603 .177 & 235.546 .640 \\
1997 a 2005 & $457^{\text {a }}$ & 506 & 3.221 .400 .517 & 2.002 .189 .543 \\
\hline
\end{tabular}

Fonte: FINEP.

a O número total de firmas não é igual ao somatório das firmas atendidas em cada ano, em virtude de que algumas firmas receberam empréstimos do ADTEN em mais de um ano. Esta também é a razão pela qual o número de operações é maior do que o número de firmas beneficiadas em cada ano.

de avaliar e financiar projetos e atividades de $\mathrm{P} \& \mathrm{D}$ das firmas industriais, os números mostram que possivelmente há uma restrição de oferta de crédito no Brasil para as atividades inovativas em geral e em especial para P\&D. ${ }^{21}$

O segundo indicador relevante do alcance do programa ADTEN é o número de empresas financiadas. $\mathrm{Na}$ indústria brasileira existem aproximadamente $80 \mathrm{mil}$ firmas industriais com mais de 10 pessoas ocupadas. No período de 1998 a 2003, na média, aproximadamente 23 mil empresas realizam inovação tecnológica todos os anos. Das empresas que realizam inovação tecnológica de produto ou processo, mais de 7 mil realizam anualmente gastos com $\mathrm{P} \& \mathrm{D}$ interno à empresa. $\mathrm{O}$ ADTEN financiou em média, no período 1998-2003, 57 empresas por ano, ou seja, o

21 Mesmo fontes privadas de crédito parecem ser muito reduzidas na indústria brasileira, como se pode constatar pelos números das pesquisas de inovação: aproximadamente $90 \%$ dos gastos em P\&D na indústria brasileira são financiados por recursos próprios das firmas inovadoras. 
ADTEN financia 0,2\% das firmas inovadoras e $0,8 \%$ das firmas que realizam investimentos em P\&D. Quando se considera o total de empresas industriais com mais de 10 pessoas ocupadas, o ADTEN cobre apenas 0,07\% das firmas brasileiras.

Com um desembolso de aproximadamente R\$ 3 bilhões entre 1997 e 2005 e com o pequeno número de firmas beneficiadas, parece que os impactos do programa estariam muito circunscritos e suas possibilidades de melhorar significativamente a produção tecnológica nacional seriam muito reduzidas.

As empresas que utilizam o programa estão fortemente concentradas no setor industrial. A Tabela 5 mostra alguns indicadores das firmas industriais beneficiárias do ADTEN, em comparação com as não-beneficiárias. As estatísticas também são apresentadas só para as firmas inovadoras e somente para as empresas com gastos em P\&D, em 2000. ${ }^{22}$

Percebe-se claramente que as firmas beneficiárias do programa têm um desempenho econômico e tecnológico bastante superior às firmas não-beneficiárias. Os gastos totais em $\mathrm{P} \& \mathrm{D}$ das firmas beneficiárias são substancialmente superiores aos gastos em P\&D das demais firmas não-beneficiárias do programa. Quando medido como proporção da receita líquida de vendas (RLV), entretanto, os gastos em $\mathrm{P} \& \mathrm{D}$ dos beneficiários equivale a $1,2 \%$ da receita, contra uma média nacional de $0,7 \%$ em 2003, mas contra uma média de 5,2\% entre o subconjunto de firmas que gasta em P\&D.

A despeito dessas diferenças, ainda não é possível afirmar que o melhor desempenho das beneficiárias seja devido ao programa. A questão fundamental é se o programa, de fato, melhorou o desempenho econômico e o esforço tecnológico das firmas beneficiárias ou, então, se essas firmas já eram mais competitivas e já investiriam mais em $\mathrm{P} \& \mathrm{D}$ mesmo sem ter acesso ao programa.

\section{Resultados econométricos}

Para responder se os programas provocam efeitos de adição ou de crowding out nos gastos privados em P\&D, dois procedimentos foram utilizados: Propensity Score Matching com um teste de diferença de médias no mesmo ano do matching e um modelo de seleção em dois estágios (Heckman, 1979). Cabe ressaltar que as firmas beneficiárias que serão incorporadas nessa avaliação são aquelas que receberam o 
TABELA 5

Indicadores selecionados das empresas industriais beneficiárias e não-beneficiárias do ADTEN - 2000

\begin{tabular}{|c|c|c|c|c|}
\hline \multirow{2}{*}{ Indicadores } & \multirow{2}{*}{$\begin{array}{l}\text { Beneficiárias } \\
\text { do ADTEN }\end{array}$} & \multicolumn{3}{|c|}{ Não-beneficiárias do ADTEN } \\
\hline & & Total & $\begin{array}{c}\text { Firmas } \\
\text { inovadoras }^{a}\end{array}$ & $\left|\begin{array}{c}\text { Firmas com } \\
\text { gastos em } \\
\text { P\&D }\end{array}\right|$ \\
\hline N. de funcionários & 743 & 68 & 116 & 207 \\
\hline Faturamento ( $R \$ 1000)$ & 157.030 & 8.488 & 18.934 & 41.738 \\
\hline Produtividade do trabalho ${ }^{2}(\mathrm{R} \$)$ & 57.847 & 18.335 & 23.740 & 31.722 \\
\hline Escolaridade média dos funcionários (anos de estudo) & 8,37 & 7,14 & 7,56 & 7,81 \\
\hline Estoque de solicitações de patentes & 1,48 & 0,09 & 0,21 & 0,48 \\
\hline Estoque de solicitações de patentes (por 100 funcionários) & 0,76 & 0,12 & 0,21 & 0,42 \\
\hline Participação de firmas estrangeiras (\%) & $10 \%$ & $3 \%$ & $6 \%$ & $9 \%$ \\
\hline Valor médio das exportações $(\mathrm{R} \$ 1000)^{3}$ & 87.579 & 8.004 & 11.676 & 17.132 \\
\hline Coeficiente de exportação ${ }^{3}$ & 0,16 & 0,15 & 0,14 & 0,12 \\
\hline Gastos em $P \& D^{4}(R \$)$ & 2.940 .360 & 55.810 & 157.050 & 441.719 \\
\hline - como proporção do faturamento(\%) & 1,2 & 0,7 & 1,9 & 5,4 \\
\hline Gastos privados em $\mathrm{P} \& \mathrm{D}^{4}(\mathrm{R} \$)$ & 2.586 .011 & 54.163 & 152.412 & 428.673 \\
\hline - como proporção do faturamento(\%) & 1,1 & 0,7 & 1,9 & 5,2 \\
\hline Participação de recursos privados nos gastos em P\&D & $88 \%$ & $97 \%$ & $97 \%$ & $97 \%$ \\
\hline $\mathrm{N}^{\circ}$ amostra & 95 & 10.231 & 5.333 & 2.600 \\
\hline $\mathrm{N}^{\circ}$ população & 138 & 71.859 & 24.581 & 9.079 \\
\hline
\end{tabular}

Fonte: IBGE, Diretoria de Pesquisas, Coordenação de Indústria, Pesquisa Industrial de Inovação Tecnológica, 2000. Elaboração: IPEA-DISET a partir da transformação dos dados obtidos na fonte e com a incorporação de dados da PIA/IBGE, SECEX/MDIC, CBE/BACEN, CEB/BACEN, ComprasNet/MPOG RAIS/MTE e FINEP.

a Empresas inovadoras são aquelas que realizaram algum tipo de inovação entre 1998 e 2000 ou que, nesse período, possuíam projetos de inovação incompletos ou inacabados.

b Valor adicionado (valor da transformação industrial) por funcionário.

c Apenas para firmas exportadoras.

d Gastos em P\&D incluem aqueles realizados internamente na firma, bem como a aquisição externa de P\&D, e foi dividido entre recursos públicos e privados. 
FNDCT entre 2000 e 2003. Excluímos da amostra das beneficiárias, portanto, as firmas que tiveram acesso ao programa em 2004 e 2005, em virtude de que a informação mais recente disponível sobre os gastos em P\&D das firmas brasileiras é de $2003 .{ }^{23}$ No caso do ADTEN, foram avaliadas as empresas que receberam financiamento entre 1997 e 2000, dado que tanto o procedimento de matching com teste de diferença de médias quanto os modelos de seleção foram aplicados em $2000 .^{24}$

Um outro conjunto de questóes diz respeito à evolução temporal de alguns indicadores econômicos das firmas beneficiárias, tais como produtividade e crescimento. As questões relevantes são se as firmas beneficiárias cresceram mais do que as não-beneficiárias e se o crescimento da produtividade também foi maior entre as primeiras. ${ }^{25}$ Para responder a essas questões, o procedimento adotado foi o PSM com diferenças em diferenças.

Nós temos, portanto, dois diferentes conjuntos de informaçôes a serem utilizados. Um deles é uma base de dados transversal: a PINTEC de 2000 para avaliar o FNDCT e a de 2003 para a avaliação do ADTEN. Outra base é longitudinal: a PIA e RAIS de 1999 a 2003 para a avaliação do FNDCT e de 1996 a 2003 para a avaliação do ADTEN. Assim, duas equaçōes de seleção (modelos probabilísticos) serão utilizadas para a construção do grupo de controle em cada um dos programas avaliados. A primeira será estimada antes do início do período de tratamento - em 1999 no caso do FNDCT e em 1996 no caso do ADTEN - e será utilizada na análise dinâmica (modelos de diferenças em diferenças). O segundo modelo probabilístico será estimado em 2003 para o FNDCT e em 2000 para o ADTEN.

\subsection{FNDCT}

\subsubsection{Propensity Score Matching}

O primeiro procedimento utilizado para a avaliação do programa foi o PSM. A Tabela A.1 (Anexo) mostra os resultados dos modelos probabilísticos utilizados para gerar os grupos de controle. De forma geral os sinais dos parâmetros foram de acordo com o esperado.

23 Mesmo para as firmas que receberam o financiamento em 2003, talvez o impacto do programa ainda não tenha tido todo o tempo necessário para se manifestar. Mesmo assim, optou-se por não retirar mais essas observações da amostra.

24 Quando os exercícios para o programa ADTEN foram concluídos, ainda não estava disponível a PINTEC de 2003.

25 Esse procedimento necessita de dados longitudinais e não foi adotado para verificar o crescimento dos gastos em P\&D. A razão é que, apesar de estarem disponíveis as duas Pesquisas de Inovação Tecnológica (de 2000 e de 2003), a interseção entre as duas pesquisas é muito pequena, o que reduziria significativamente o número de firmas que poderiam ser avaliadas em termos das taxas de crescimento dos seus esforços tecnológicos. 
O modelo probabilístico foi estimado para:

1) toda a amostra;

2) somente para as firmas inovadoras; e

2) somente para as firmas com gastos em $P \& D$.

O objetivo de construir grupos de controle apenas com firmas inovadoras ou firmas que possuem gastos em $\mathrm{P} \& \mathrm{D}$ foi o de reduzir a heterogeneidade entre as firmas e dar mais robustez ao matching. Após o procedimento de matching, o próximo passo é comparar as diferenças entre os grupos de firmas: o das beneficiárias do FNDCT e o grupo de controle na amostra total e em cada subamostra utilizada. Os resultados desses testes estão reportados na Tabela 6.

Sobre o impacto do FNDCT nos gastos em P\&D das firmas, a Tabela 6 mostra que, na amostra completa, tanto o valor absoluto dos dispêndios quanto o valor relativo ao faturamento são maiores no conjunto das beneficiárias do que no grupo de controle. Nas duas outras subamostras, os resultados não foram tão expressivos. Para as firmas inovadoras. apenas o valor dos gastos em $\mathrm{P} \& \mathrm{D}$ como proporção do faturamento é significativamente maior entre as beneficiárias. Para as firmas com gasto em $\mathrm{P} \& \mathrm{D}$, entretanto, a diferença significativa está nos gastos em $\mathrm{P} \& \mathrm{D}$ como proporção do faturamento, novamente em favor das beneficiárias. Em relação à produtividade, o diferencial em favor das beneficiárias foi significativo na amostra completa e na subamostra que possui dispêndios em $\mathrm{P} \& \mathrm{D}$.

Outro objetivo dessa análise é saber se as empresas participantes do programa apresentam taxas de crescimento do produto e da produtividade maiores do que as não-participantes. Para fazer essa avaliação, o procedimento mais adequado é o Propensity Score Matching com diferenças em diferenças.

Nesse caso, o grupo de controle foi estabelecido, por meio do modelo probabilístico mostrado na Tabela A.2 (Anexo), antes do período de vigência do programa (1999), e o período de tratamento vai de 1999 a $2003 .{ }^{26}$ A partir desse grupo de controle, realizamos um teste de diferença de médias para a taxa de crescimento do faturamento, do número de funcionários e da produtividade das firmas nesse período. ${ }^{27}$

26 Em outras palavras, foram avaliadas as taxas de variação de algumas variáveis relevantes entre 1999 e 2003 para as beneficiárias vis-à-vis o grupo de controle estabelecido para elas em 1999.

27 A taxa de crescimento foi calculada como: [( valor em 2003 - valor em 1999) / valor em 1999] para todas as variáveis da Tabela 7. Uma diferença importante é que, para a estimação desse modelo, utilizamos apenas as informações da Pesquisa Industrial Anual, dado que não existia a pesquisa de inovação tecnológica neste ano. Por fim, utilizamos, da PIA, apenas as empresas com mais de 30 funcionários, novamente para reduzir a heterogeneidade existente na amostra completa. 
Impactos do ADTEN e do FNDCT sobre o Desempenho e os Esforços Tecnológicos das Firmas Industriais Brasileiras

TABELA 6

Teste de diferença de médias em variáveis selecionadas para firmas que receberam suporte do FNDCT e para o grupo de controle - 2003

\begin{tabular}{|c|c|c|c|c|c|c|c|c|c|}
\hline \multirow[b]{2}{*}{ Variáveis } & \multicolumn{3}{|c|}{ Amostra total } & \multicolumn{3}{|c|}{ Firmas inovadoras } & \multicolumn{3}{|c|}{ Firmas com gastos em $P \& D$} \\
\hline & $\begin{array}{l}\text { Grupo de } \\
\text { controle }\end{array}$ & $\begin{array}{l}\text { Benefi- } \\
\text { ciárias }\end{array}$ & $\mathrm{t}$ & $\begin{array}{l}\text { Grupo de } \\
\text { controle }\end{array}$ & $\begin{array}{l}\text { Benefi- } \\
\text { ciárias }\end{array}$ & $\mathrm{t}$ & $\begin{array}{l}\text { Grupo de } \\
\text { controle }\end{array}$ & $\begin{array}{l}\text { Benefi- } \\
\text { ciárias }\end{array}$ & $\mathrm{t}$ \\
\hline $\begin{array}{l}\text { Faturamento } \\
\text { (R\$1.000) }\end{array}$ & 275.923 & $703.829 * *$ & $-1,84$ & 912.640 & 821.575 & 0,18 & 405.971 & 774.383 & $-1,15$ \\
\hline № de funcionários & 1.183 & 1.624 & $-0,89$ & 1.567 & 1.609 & $-0,06$ & 1.953 & 1.372 & 0,57 \\
\hline Produtividade $^{\mathrm{a}}(\mathrm{R} \$)$ & 80.921 & $132.203^{* *}$ & $-2,25$ & 115.678 & 144.340 & $-0,80$ & 87.797 & $156.020 * *$ & $-2,05$ \\
\hline $\begin{array}{l}\text { Gastos em P\&D } \\
(R \$ 1.000)\end{array}$ & 1.276 & $3.672^{* *}$ & $-2,29$ & 6.935 & 4.320 & 0,44 & 996 & $4.327^{\star \star *}$ & $-2,85$ \\
\hline $\begin{array}{l}\text { - como proporção } \\
\text { do faturamento }(\%)\end{array}$ & 1,12 & $3,00 * *$ & $-2,15$ & 0,96 & $3,67 * *$ & $-2,57$ & 2,62 & 3,94 & $-0,71$ \\
\hline $\begin{array}{l}\text { Gastos privados em } \\
P \& D^{b}(R \$ 1.000)\end{array}$ & 1.252 & 3.510 ** & $-2,18$ & 4.935 & 4.121 & 0,48 & 848 & $4.165^{* * *}$ & $-2,87$ \\
\hline $\begin{array}{l}\text { - como proporção } \\
\text { do faturamento (\%) }\end{array}$ & 1,11 & $2,74^{* *}$ & $-1,99$ & 0,96 & $3,35^{* *}$ & $-2,42$ & 2,41 & 3,60 & $-0,66$ \\
\hline $\mathrm{N}^{\circ}$ de firmas 28 & 44 & 44 & & 35 & 35 & & 33 & 33 & \\
\hline
\end{tabular}

Fonte: IBGE, Diretoria de Pesquisas, Coordenação de Indústria, Pesquisa industrial - Inovação tecnológica 2000. Elaboração: IPEA-DISET a partir da transformação dos dados obtidos na fonte e com a incorporação de dados da PIA/ IBGE, SECEX/MDIC, CBE/BACEN, CEB/BACEN, ComprasNet/MPOG RAIS/MTE e FINEP.

a Valor adicionado por funcionário.

${ }^{\mathrm{b}}$ Incluem os gastos internos em P\&D e a aquisição externa de P\&D. Esses gastos podem ser divididos em gastos privados (financiados com recursos próprios ou de terceiros) e públicos (financiados por fontes públicas).

Obs.: $\left(^{*}\right),(* *),(* *)$ denotam variáveis significativas a $10 \%, 5 \%$ e $1 \%$ respectivamente.

28 O número de firmas beneficiárias analisadas caiu das 49 presentes no modelo probabilístico para 44 firmas nos testes de diferenças de médias na amostra completa, para 35 na sub-amostra das firmas inovadoras e para 33 na subamostra de firmas com gastos em P\&D. Essa redução ocorre devido à dificuldade de encontrar firmas estreitamente similares às beneficiárias, e que possam constituir o grupo de controle para elas. 
TABELA 7

Testes de diferenças de médias para as taxas de crescimento de variáveis selecionadas das firmas beneficiárias e das não-beneficiárias (grupo de controle) pelo FNDCT entre 1999 e 2003

\begin{tabular}{|c|c|c|c|}
\hline & Grupo de controle & Beneficiárias & $\mathrm{t}$ \\
\hline Faturamento & $-0,001$ & 0,20 & $-1,6^{\text {ns }}$ \\
\hline № de funcionários & 0,07 & 0,19 & $-1,3^{\text {ns }}$ \\
\hline Produtividade do trabalho & $-0,049$ & 0,27 & $-1,28$ ns \\
\hline $\mathrm{N}$ & 41 & 41 & \\
\hline
\end{tabular}

Fonte: IBGE, Diretoria de Pesquisas, Coordenação de Indústria, Pesquisa Industrial de Inovação Tecnológica, 2000. Elaboração: IPEA-DISET a partir da transformação dos dados obtidos na fonte e com a incorporação de dados da PIAV IBGE, SECEX/MDIC, CBE/BACEN, CEB/BACEN, ComprasNet/MPOG RAIS/MTE e FINEP.

Obs.: $\left(^{*}\right),(* *),(* *)$ denotam variáveis significativas a $10 \%, 5 \%$ e $1 \%$ respectivamente; (ns) denota testes não-significativos. Receita total e produtividade foram deflacionadas pelo IPA.

A Tabela 7 mostra os resultados desses testes que não mostram nenhuma diferença estatisticamente significativa entre beneficiárias e não-beneficiárias, em nenhuma das variáveis analisadas. A hipótese nula, de que o grupo de controle e o grupo de tratamento tiveram as mesmas taxas de crescimento, foi aceita para todas as variáveis, apesar de as beneficiárias terem apresentado maiores taxas de crescimento em todas elas.

Uma das razões para a não-significância estatística das diferenças nas taxas de crescimento pode estar relacionada com o período de análise que é bastante curto para que se possam observar efeitos significativos do programa. Além disso, a literatura sobre inovação também alerta para a possibilidade de que as firmas percam produtividade logo após a implementação de uma inovação. Os ganhos de produtividade derivados de atividades tecnológicas requereriam, portanto, horizontes temporais maiores para serem verificados.

\subsubsection{Modelos de seleção em dois estágios}

O primeiro estágio desse procedimento, novamente, consiste em um modelo probabilístico que será o mesmo que foi estimado para o PSM para as firmas gastaram em P\&D (última coluna da Tabela A.1 do Anexo). Nesse caso, estaremo-nos perguntando se, entre as firmas que possuem atividades de $\mathrm{P} \& \mathrm{D}$, as beneficiárias do FNDCT investiram mais recursos nessa atividade do que as não-beneficiárias. Este 
é o modelo probabilístico que será usado para o cálculo da razão inversa de Mills (equaçōes 4 e 5).

Depois disso, utiliza-se a razão inversa de Mills como variável explicativa nos modelos OLS (equações de tratamento) estimados para toda a amostra que gasta em P\&D e para beneficiárias e não-beneficiárias separadamente. A Tabela 8 mostra os resultados da estimação desses modelos, bem como de um modelo de mínimos quadrados convencional com uma dummy para firma beneficiária do FNDCT. ${ }^{29}$

A primeira consideração relevante sobre os resultados da Tabela 8 é de que, de fato, a significância do parâmetro lambda evidencia a existência de viés de seleção na amostra considerada. O conjunto das variáveis explicativas também apresenta os sinais esperados e grande parte delas é estatisticamente significativa nos dois modelos em que os graus de liberdade são maiores.

Os efeitos do tratamento calculados a partir de um modelo OLS convencional e pelo modelo de Heckman são reportados na Tabela 9, que mostra que as firmas beneficiárias possuem gastos em $\mathrm{P} \& \mathrm{D}$ significativamente superiores às firmas não-beneficiárias similares. $\mathrm{O}$ efeito do programa é ainda maior, uma vez corrigido o viés de seleção. $\mathrm{O}$ efeito médio do tratamento (ATE) foi calculado de duas formas distintas, como demonstrado na seção metodológica. A primeira, utilizando as equações estimadas para beneficiárias e não-beneficiárias separadamente, (ATE1) e a segunda (ATE2) foi calculada com base na equação estimada para a amostra completa.

Além de não serem observados efeitos de crowding out decorrentes do FNDCT nos gastos privados em $\mathrm{P} \& \mathrm{D}$, também se pode observar efeitos positivos e significativos do programa nesses gastos. Os efeitos do tratamento mostram que as firmas participantes do programa gastam aproximadamente de $50 \%$ a $90 \%^{30}$ a mais em $\mathrm{P} \& \mathrm{D}$ do que as firmas não-participantes.

Este trabalho também tem o objetivo de verificar o impacto do programa no desempenho econômico das firmas, especialmente sobre a produtividade. Assim, aplicamos os modelos de seleção também para a produtividade da firma. A equação de seleção utilizada é a mesma utilizada anteriormente para todas as firmas (primeira coluna da Tabela A.1 do Anexo).

29 Para evitar problemas de identificação e de desvios-padrão elevados, é necessário que algumas das variáveis do segundo estágio sejam diferentes das utilizadas no primeiro estágio. Assim, na equação de tratamento, as dummies, para se avaliar a solvência da firma, não foram utilizadas. Por outro lado, uma nova variável foi adicionada à equação de tratamento: a escolaridade média da mão de obra da firma.

30 Dado que a variável dependente se encontra na forma logarítmica, esse resultado foi obtido pela seguinte transformação: (exp (ATE) - 1)*100. 
TABELA 8

Modelos de mínimos quadrados para o logaritmo dos gastos privados em $P \& D$ (apenas para firmas com gastos em P\&D maiores que zero) - 2003

\begin{tabular}{|c|c|c|c|c|c|c|c|c|}
\hline \multirow{3}{*}{ Variáveis explicativas } & \multirow{2}{*}{\multicolumn{2}{|c|}{ OLS }} & \multicolumn{6}{|c|}{ Modelos de seleção } \\
\hline & & & \multicolumn{2}{|c|}{ Beneficiárias } & \multicolumn{2}{|c|}{ Não-beneficiárias } & \multicolumn{2}{|c|}{ Todas } \\
\hline & $\beta$ & $\mathrm{t}$ & $\beta$ & $\mathrm{t}$ & $\beta$ & $\mathrm{t}$ & $\beta$ & $\mathrm{t}$ \\
\hline Intercepto & $6,53 * * *$ & 0,24 & $19,83^{* * *}$ & 5,07 & $6,29 * * *$ & 0,33 & $5,95 * * *$ & 0.31 \\
\hline $\begin{array}{l}\text { Dummy para beneficiárias } \\
\text { do FNDCT }\end{array}$ & $1,03 * * *$ & 0,32 & - & - & - & - & $5,45^{* * *}$ & 0,80 \\
\hline $\begin{array}{l}\text { № de funcionários } \\
\text { (LOG) }\end{array}$ & $0,66 * * *$ & 0,03 & 0,2 & 0,27 & $0,57 * * *$ & 0,03 & $0,62 * * *$ & 0.03 \\
\hline $\begin{array}{l}\text { Escolaridade média } \\
\text { dos funcionários }\end{array}$ & $0,16 * * *$ & 0,02 & $0,28 * *$ & 0,12 & $0,25^{* * *}$ & 0,02 & $0,26 * * *$ & 0.02 \\
\hline $\begin{array}{l}\text { Idade da firma } \\
\text { (LOG) }\end{array}$ & $-0,03$ & 0,04 & $-0,25$ & 0,51 & $-0,04$ & 0,05 & $-0,03$ & 0.05 \\
\hline $\begin{array}{l}\text { Firmas com patentes } \\
\text { (em 2002) }\end{array}$ & $0,18^{*}$ & 0,10 & 0,20 & 0,39 & $0,18^{* *}$ & 0,08 & $0,21 * * *$ & 0.08 \\
\hline $\begin{array}{l}\text { Firma exportadora } \\
\text { (em 2002) }\end{array}$ & $0,35^{* * *}$ & 0,08 & $-1,21$ & 0,77 & 0,11 & 0,09 & $0,18 * *$ & 0.08 \\
\hline Firma estrangeira & $0,25^{\star *}$ & 0,11 & $1,56^{*}$ & 0,78 & $0,47 * * *$ & 0,10 & $0,31 * * *$ & 0.09 \\
\hline $\begin{array}{l}\text { Dummy para região } \\
\text { Sul/Sudeste }\end{array}$ & $0,23 * * *$ & 0,07 & $-1,33 * * *$ & 0,48 & 0,12 & 0,07 & $0,14^{* * *}$ & 0.08 \\
\hline $\begin{array}{l}\text { Dummy para setor } \\
\text { intensivo em tecnologia }\end{array}$ & $0,55 * * *$ & 0,06 & $-0,66$ & 0,67 & $0,41 * * *$ & 0,08 & $0,52 * * *$ & 0.07 \\
\hline $\begin{array}{l}\text { Lambda } \\
\text { (razão inversa de Mills) }\end{array}$ & - & - & $-2,89 * * *$ & 0,75 & $-4,91 * * *$ & 0,88 & $-2,10 * * *$ & 0,36 \\
\hline $\mathrm{F}$ & & & 15 & & 19 & & 190 & \\
\hline $\mathrm{R}^{2}$ ajustado & & & 0.7 & & 0. & & 0.5 & \\
\hline № de observações & 1.7 & & 40 & & 1.7 & & 1.7 & \\
\hline
\end{tabular}

Fonte: IBGE, Diretoria de Pesquisas, Coordenação de Indústria, Pesquisa Industrial de Inovação Tecnológica, 2000. Elaboração: IPEA-DISET a partir da transformação dos dados obtidos na fonte e com a incorporação de dados da PIAV IBGE, SECEX/MDIC, CBE/BACEN, CEB/BACEN, ComprasNet/MPOG RAIS/MTE e FINEP.

Obs.: $\left(^{*}\right),\left({ }^{* *}\right),(* * *)$ denotam variáveis significativas a $10 \%, 5 \%$ e $1 \%$ respectivamente. 
TABELA 9

Efeitos médios do tratamento (participação no FNDCT) sobre os gastos privados em P\&D das firmas a partir de diferentes especificações dos modelos - 2003

Modelo

Mínimos quadrados

Modelos de seleção (firmas beneficiárias versus

não-beneficiárias) - ATE1

Modelos de seleção (para todas as firmas) - ATE2
Impacto do FNDCT

Efeito do tratamento (ATE)

Valor de $\mathrm{t}$

1,03

$* * *$

3,22

0,64

5,07

0,41

2,97

Fonte: IBGE, Diretoria de Pesquisas, Coordenação de Indústria, Pesquisa industrial - Inovação tecnológica 2000. Elaboração: IPEA-DISET a partir da transformação dos dados obtidos na fonte e com a incorporação de dados da PIA/IBGE, SECEX/MDIC, CBE/BACEN, CEB/BACEN, ComprasNet/MPOG RAIS/MTE e FINEP.

Obs.: $\left(^{*}\right),(* *),(* * *)$ denotam variáveis significativas a $10 \%, 5 \%$ e $1 \%$ respectivamente.

A Tabela 10 mostra os resultados dos modelos de seleção e do modelo de mínimos quadrados para o logaritmo da produtividade da firma. Para a produtividade, a razão inversa de Mills não foi significativa. Assim, o impacto do FNDCT sobre a produtividade da firma pode ser adequadamente avaliado a partir do modelo convencional de mínimos quadrados. Nele, a dummy para empresa participante do FNDCT não foi significativa, sugerindo que os eventuais impactos do programa sobre a produtividade, se houverem, são desprezíveis. Dado que o viés de seleção não foi observado para essa variável, não se fez necessário o cálculo do efeito médio do tratamento, como no procedimento anterior.

A inexistência de efeitos significativos do programa sobre a produtividade das firmas pode ser derivada de vários fatores, além da ineficácia do programa em ampliar a produtividade das beneficiárias. Em primeiro lugar, o período de tempo da análise é muito curto - no máximo de três anos. Provavelmente, os impactos sobre a produtividade pudessem ser percebidos a partir de um horizonte de tempo mais longo do que esse. Em segundo lugar, o programa não foi desenhado para aumentar a produtividade das empresas, e, sim, para aumentar seus esforços tecnológicos e estimular as inovações tecnológicas nas empresas participantes. Dessa forma, impactos sobre a produtividade seriam indiretos, derivados das atividades tecnológicas das empresas. 
TABELA 10

Modelos de mínimos quadrados e de seleção para a variável dependente:

logaritmo da produtividade da empresa em 2003

\begin{tabular}{|c|c|c|c|c|c|c|c|c|}
\hline \multirow{3}{*}{ Variáveis explicativas } & & & \multicolumn{6}{|c|}{ Modelos de seleção } \\
\hline & \multicolumn{2}{|c|}{ OLS } & \multicolumn{2}{|c|}{ Beneficiárias } & \multicolumn{2}{|c|}{ Não-beneficiárias } & \multicolumn{2}{|c|}{ Todas } \\
\hline & $\beta$ & t value & $\beta$ & $\mathrm{t}$ value & $\beta$ & $\mathrm{t}$ & $\beta$ & $\mathrm{t}$ value \\
\hline Intercepto & $7,54 * * *$ & 0,11 & $8,78 * * *$ & 2,08 & $6,22 * * *$ & 0,11 & $6,22 * * *$ & 0,11 \\
\hline $\begin{array}{l}\text { Dummy para beneficiárias } \\
\text { do FNDCT }\end{array}$ & 0,78 & 0,49 & - & - & - & - & 0,65 & 0,7 \\
\hline $\begin{array}{l}\text { № de funcionários } \\
\text { (LOG) }\end{array}$ & $0,11 * * *$ & 0,01 & 0,002 & 0,12 & $0,22 * * *$ & 0,01 & $0,22 * * *$ & 0,01 \\
\hline $\begin{array}{l}\text { Escolaridade média } \\
\text { dos funcionários }\end{array}$ & $0,06 * * *$ & 0,01 & $0,32 * * *$ & 0,05 & $0,14^{* * *}$ & 0,01 & $0,14 * * *$ & 0,01 \\
\hline $\begin{array}{l}\text { Idade da firma } \\
\text { (LOG) }\end{array}$ & $0,10 * * *$ & 0,02 & 0,32 & 0,24 & $0,20 * * *$ & 0,02 & $0,20 * * *$ & 0,02 \\
\hline $\begin{array}{l}\text { Firmas com patentes } \\
\text { (em 2002) }\end{array}$ & 0,11 & 0,09 & 0,01 & 0,18 & $-0,05$ & 0,05 & $-0,06$ & 0,05 \\
\hline $\begin{array}{l}\text { Firma exportadora } \\
\text { (em 2002) }\end{array}$ & $0,54 * * *$ & 0,05 & $-0,46$ & 0,33 & $0,44 * * *$ & 0,04 & $0,43 * * *$ & 0,04 \\
\hline Firma estrangeira & $0,79 * * *$ & 0,11 & 0,45 & 0,32 & $0,48 * * *$ & 0,06 & $0,48 * * *$ & 0,05 \\
\hline $\begin{array}{l}\text { Dummy para região } \\
\text { Sul/Sudeste }\end{array}$ & $0,26 * * *$ & 0,03 & $-0,85 * * *$ & 0,19 & $0,24 * * *$ & 0,03 & $0,23 * * *$ & 0,03 \\
\hline $\begin{array}{l}\text { Dummy para setor } \\
\text { intensivo em tecnologia }\end{array}$ & $0,56 * * *$ & 0,04 & $-0,35$ & 0,28 & $0,38 * * *$ & 0,03 & $0,37 * * *$ & 0,03 \\
\hline $\begin{array}{l}\text { Lambda } \\
\text { (razão inversa de Mills) }\end{array}$ & - & - & $-0,49$ & 0,30 & 0,32 & 0,56 & 0,07 & 0,26 \\
\hline $\mathrm{F}$ & & & 16 & & 406 & & 37 & \\
\hline$R^{2}$ ajustado & & & 0.7 & & 0.2 & & 0. & \\
\hline № de observações & 10. & 44 & 4 & & 10.0 & & 10. & 44 \\
\hline
\end{tabular}

Fonte: IBGE, Diretoria de Pesquisas, Coordenação de Indústria, Pesquisa Industrial de Inovação Tecnológica, 2000. Elaboração: IPEA-DISET a partir da transformação dos dados obtidos na fonte e com a incorporação de dados da PIA/ IBGE, SECEX/MDIC, CBE/BACEN, CEB/BACEN, ComprasNet/MPOG RAIS/MTE e FINEP.

Obs.: $\left(^{*}\right),\left({ }^{* *}\right),(* * *)$ denotam variáveis significativas a $10 \%, 5 \%$ e $1 \%$ respectivamente. 


\subsection{ADTEN}

Todos os procedimentos adotados para a avaliação do FNDCT também o foram para a avaliação do ADTEN. A especificidade em relação ao ADTEN é que o período de abrangência do programa é maior do que no caso do FNDCT, o que, de modo geral, nos dá mais graus de liberdade nos procedimentos econométricos.

\subsubsection{Propensity Score Matching}

O modelo probabilístico utilizado no primeiro passo do Propensity Score Machting apresentou, de modo geral, os sinais esperados dos parâmetros, uma boa parte deles foram estatisticamente significativos e os resultados globais dos modelos mostraram consistência na escolha das variáveis (Tabela A.3 do Anexo).

Depois de estimar o modelo probabilístico em 2000 e estabelecer o matching entre beneficiárias e grupo de controle, aplicamos o teste de diferença de médias entre os dois grupos, também em 2000 (Tabela 11). O número de firmas analisadas caiu para 92, na amostra completa, 73 na amostra de firmas inovadoras e para 52 na amostra de firmas com gastos em P\&D. A razão para a redução do número de firmas é, em primeiro lugar, a falta de pares adequados - ou seja, com características similares - a algumas das firmas beneficiárias. Assim, algumas firmas beneficiárias não encontraram correspondentes no grupo de controle e foram excluídas da amostra. Além disso, nem todas as beneficiárias são inovadoras ou possuem gastos em $\mathrm{P} \& \mathrm{D}$, o que fez com que, nessas subamostras, o número de firmas se reduzisse ainda mais. ${ }^{31}$

Uma das principais variáveis a ser analisada é o impacto do ADTEN sobre os gastos em P\&D das firmas beneficiárias - tanto em termos absolutos quanto na proporção desses gastos em relação ao faturamento. $\mathrm{Na}$ amostra completa observamos um efeito positivo e significativo do programa no valor dos gastos em P\&D como proporção do faturamento das firmas participantes. Estas últimas comprometem mais do que o dobro do seu faturamento em $P \& D$ quando comparadas às firmas do grupo de controle - mesmo quando consideramos apenas os gastos privados em P\&D.

Quando consideramos apenas o grupo de empresas inovadoras, a diferença no esforço tecnológico (P\&D em relação à receita) desaparece. Entretanto, observamos diferenças significativas no valor absoluto dos gastos em P\&D das participantes do programa em relação ao grupo de controle. Nessa amostra, a produtividade também foi

31 critério de ser inovadora ou possuir gastos em P\&D foi aplicado tanto ao grupo de controle, quanto às empresas participantes do programa. 
TABELA 11

Testes de diferenças de médias para variáveis selecionadas das empresas beneficiárias e do grupo de controle -2000

\begin{tabular}{|c|c|c|c|c|c|c|c|c|c|}
\hline \multirow{2}{*}{ Variáveis } & \multicolumn{3}{|c|}{ Amostra total } & \multicolumn{3}{|c|}{ Firmas inovadoras } & \multicolumn{3}{|c|}{ Firmas com gastos em $P \& D$} \\
\hline & $\begin{array}{l}\text { Grupo de } \\
\text { controle }\end{array}$ & $\begin{array}{l}\text { Benefi- } \\
\text { ciárias }\end{array}$ & $\mathrm{t}$ & $\begin{array}{l}\text { Grupo de } \\
\text { controle }\end{array}$ & $\begin{array}{l}\text { Benefi- } \\
\text { ciárias }\end{array}$ & $\mathrm{t}$ & $\begin{array}{l}\text { Grupo de } \\
\text { controle }\end{array}$ & $\begin{array}{l}\text { Benefi- } \\
\text { ciárias }\end{array}$ & $\mathrm{t}$ \\
\hline $\begin{array}{l}\text { Faturamento } \\
\text { (R\$1.000) }\end{array}$ & 152.633 & 147.983 & 0,06 & 84.988 & 161.675 & $-1,39$ & 118.188 & 200.984 & $-1,04$ \\
\hline № de funcionários & 773 & 816 & $-0,20$ & 800 & 697 & 0,51 & 686 & 876 & $-0,91$ \\
\hline Produtividade ${ }^{\mathrm{a}}(\mathrm{R} \$)$ & 49.639 & 59.400 & $-0,96$ & 38.124 & $64.421 * *$ & $-2,44$ & 57.782 & 67.307 & $-0,63$ \\
\hline $\begin{array}{l}\text { Gastos em P\&D } \\
(\mathrm{R} \$ 1.000)\end{array}$ & 1.689 & 1.504 & 0,13 & 468 & $1.849^{*}$ & $-1,93$ & 796 & 2.329 & $-1,58$ \\
\hline $\begin{array}{l}\text { - como proporção } \\
\text { do faturamento } \\
(\%)\end{array}$ & 0,53 & $1,36 * *$ & $-2,01$ & 1,50 & 1,68 & $-0,31$ & 1,65 & 2,23 & $-0,85$ \\
\hline $\begin{array}{l}\text { Gastos privados } \\
\text { em } P \& D^{b}(R \$ 1.000)\end{array}$ & 1.663 & 1.454 & 0,15 & 407 & $1.785^{\star}$ & $-1,94$ & 747 & 2.240 & $-1,52$ \\
\hline $\begin{array}{l}\text { - como proporção } \\
\text { do faturamento }\end{array}$ & 0,52 & $1,18^{* *}$ & $-2,17$ & 1,44 & 1,46 & $-0,05$ & 1,57 & 1,92 & $-0,71$ \\
\hline № de firmas & 92 & 92 & & 73 & 73 & & 52 & 52 & \\
\hline
\end{tabular}

Fonte: IBGE, Diretoria de Pesquisas, Coordenação de Indústria, Pesquisa Industrial de Inovação Tecnológica, 2000. Elaboração: IPEA-DISET a partir da transformação dos dados obtidos na fonte e com a incorporação de dados da PIA/ IBGE, SECEX/MDIC, CBE/BACEN, CEB/BACEN, ComprasNet/MPOG RAIS/MTE e FINEP.

a Valor adicionado por funcionário.

${ }^{b}$ Incluem os gastos internos em P\&D e a aquisição externa de P\&D. Esses gastos podem ser divididos em gastos privados (financiados com recursos próprios ou de terceiros) e públicos (financiados por fontes públicas).

Obs.: $\left(^{*}\right),\left({ }^{* *}\right),\left({ }^{* *}\right)$ denotam variáveis significativas a $10 \%, 5 \%$ e $1 \%$ respectivamente. 
maior para as empresas participantes do programa. Na amostra de firmas com gastos em P\&D, nenhuma diferença foi observada em nossas variáveis de resultado.

Esses resultados sugerem um impacto positivo do programa sobre os gastos em P\&D das empresas participantes. Muito embora os resultados desse procedimento ainda sejam pouco robustos. Entretanto, uma afirmação já é possível fazer. Nada indica, a partir desses resultados, que os gastos públicos representados pelos empréstimos do ADTEN estejam deslocando os gastos privados em P\&D. Ou seja, mesmo a partir desse procedimento mais simples, é possível rejeitar a hipótese de crowding out. Vale lembrar que, mesmo quando os resultados não são estatisticamente significativos, os gastos médios de P\&D das beneficiárias (seja em termos absolutos seja como proporção do faturamento) são sempre maiores entre as firmas participantes do programa.

Para avaliar se as beneficiárias do ADTEN cresceram mais do que o grupo de controle ou se tiveram aumentos superiores de produtividade, utilizaremos os modelos de diferenças em diferenças tal como no caso do FNDCT. Como o período de abrangência do programa é maior, o modelo probabilístico para a constituição do grupo de controle foi estimado para o ano de 1996 (Tabela A.4 do Anexo) e o período de tratamento será de 1997 até 2003. Dado que, em 1996, não existia a pesquisa de inovação tecnológica, utilizamos como variáveis explicativas apenas as variáveis disponíveis na PIA. Os sinais das variáveis explicativas comportaram-se como esperado e, exceto algumas dummies para o grau de solvência da firma, a idade e o market share, as demais variáveis foram significativas.

Uma vez criado o grupo de controle, o teste de diferença de médias foi aplicado para as taxas de crescimento das variáveis no período de 1996 até 2003 entre os dois grupos de firmas: as beneficiárias e o grupo de controle. $\mathrm{O}$ número de empresas beneficiárias avaliado foi de 118 empresas e os resultados dos testes encontram-se na Tabela 12.

Os resultados apresentados nessa tabela mostram que a taxa de crescimento do faturamento e do emprego foi maior, no período, entre as empresas beneficiadas pelo ADTEN do que entre as empresas do grupo de controle. Ou seja, a hipótese nula de que essas taxas de crescimento são iguais foi rejeitada nessas duas variáveis.

No caso da produtividade, por sua vez, os resultados não-significativos indicam que não foi possível rejeitar a hipótese nula sobre a igualdade de taxas de crescimento, entre os dois grupos, no período. Novamente aqui, o período de análise não é tão longo a ponto de que impactos do programa sobre a produtividade possam ser avaliados precisamente. 
TABELA 12

Testes de diferenças de médias para as taxas de crescimento de variáveis selecionadas das firmas beneficiárias e das não-beneficiárias do ADTEN entre 1996 e 2003

\begin{tabular}{lccc}
\hline \multicolumn{1}{c}{ Variáveis } & \multicolumn{3}{c}{ Taxas de crescimento } \\
\cline { 2 - 3 } & Grupo de controle & Beneficiárias & Estatística t \\
Faturamento & 0,12 & 0,76 & $2,58^{* * *}$ \\
№ de empregados & $-0,04$ & 0,75 & $-3,32^{* * *}$ \\
Produtividade & 0,15 & 0,14 & 0,11 \\
№ de firmas & 118 & 118 & \\
\hline
\end{tabular}

Fonte: IBGE, Diretoria de Pesquisas, Coordenação de Indústria, Pesquisa Industrial de Inovação Tecnológica, 2000. Elaboração: IPEA-DISET a partir da transformação dos dados obtidos na fonte e com a incorporação de dados da PIA/ IBGE, SECEX/MDIC, CBE/BACEN, CEB/BACEN, ComprasNet/MPOG RAIS/MTE e FINEP.

Obs.: $\left({ }^{*}\right),\left({ }^{* *}\right),\left({ }^{* *}\right)$ denotam variáveis significativas a $10 \%, 5 \%$ e $1 \%$ respectivamente. Receita total e produtividade foram deflacionadas pelo IPA.

\subsubsection{Modelos de seleção em dois estágios}

Assim como no caso do FNDCT, aplicamos aos dados os modelos de seleção em dois estágios. As variáveis explicativas utilizadas no primeiro estágio e no segundo estágio são as mesmas adotadas para a avaliação do FNDCT e já foram descritas anteriormente. $\mathrm{O}$ modelo probabilístico utilizado para o cálculo da razão inversa de Mills é aquele apresentado na última coluna da Tabela A.3 (Anexo).

Os resultados da estimação do segundo estágio dos modelos de seleção (equações de tratamento) estão expressos na Tabela 13. Novamente, estimamos um modelo convencional de mínimos quadrados para fins de comparação com os modelos de seleção.

As variáveis explicativas foram, na sua maior parte, significativas, exceto pelo modelo estimado apenas para as empresas beneficiárias, em que os graus de liberdade são menores. Da mesma forma, apresentaram de modo geral os sinais previstos. A razão inversa de Mills foi significativa em todos os modelos de seleção, apontando para a existência de viés de seleção na amostra.

Com relação ao impacto do programa sobre os gastos em P\&D das empresas, o modelo de mínimos quadrados - sem a correção para o viés de seleção - mostra 
Impactos do ADTEN e do FNDCT sobre o Desempenho e os Esforços Tecnológicos das Firmas Industriais Brasileiras

TABELA 13

Modelos de seleção e de mínimos quadrados para o logaritmo dos gastos privados em $P \& D$ das firmas industriais brasileiras (apenas para empresas com gastos em P\&D maiores que zero) - 2000

\begin{tabular}{|c|c|c|c|c|c|c|c|c|}
\hline & \multirow[b]{3}{*}{$\beta$} & \multirow[b]{3}{*}{$\mathrm{t}$ value } & \multicolumn{6}{|c|}{ Modelos de seleção } \\
\hline & & & \multicolumn{2}{|c|}{ Beneficiárias } & \multicolumn{2}{|c|}{ Não-beneficiárias } & \multicolumn{2}{|c|}{ Todas } \\
\hline & & & $\beta$ & $\mathrm{t}$ value & $\beta$ & $\mathrm{t}$ & $\beta$ & $\mathrm{t}$ value \\
\hline Intercepto & $5,11 * * *$ & 24,70 & $18,16^{* * *}$ & 3,36 & $5,55^{* * *}$ & 19,93 & $5,29 * * *$ & 0,11 \\
\hline $\begin{array}{l}\text { Dummy para beneficiária } \\
\text { do ADTEN }\end{array}$ & 0,36 & 1,22 & - & - & - & - & $5,43 * * *$ & 0,7 \\
\hline № de funcionários (LOG) & $0,67 * * *$ & 25,47 & 0,06 & 0,17 & $0,62 * * *$ & 18,74 & $0,67 * * *$ & 0,01 \\
\hline $\begin{array}{l}\text { Escolaridade média } \\
\text { dos funcionários }\end{array}$ & $0,14^{* * *}$ & 8,65 & $0,29 * *$ & 2,01 & $0,23^{* * *}$ & 12,61 & $0,23 * * *$ & 0,01 \\
\hline Idade da firma (LOG) & $0,19 * * *$ & 4,91 & $-0,11$ & $-0,20$ & 0,05 & 1,01 & 0,05 & 0,02 \\
\hline Firma com patentes (1998) & $0,36 * * *$ & 3,45 & 0,32 & 0,65 & $0,19 * *$ & 2,32 & $0,23 * * *$ & 0,05 \\
\hline Firma exportadora (1999) & $0,32 * * *$ & 4,40 & $-0,48$ & $-0,69$ & 0,07 & 0,93 & $0,13^{*}$ & 0,04 \\
\hline Firma estrangeira & $0,46 * * *$ & 4,36 & 1,91 * & 1,88 & $0,59 * * *$ & 6,22 & $0,45^{* * *}$ & 0,05 \\
\hline $\begin{array}{l}\text { Dummy para região } \\
\text { Sul/Sudeste }\end{array}$ & $0,19 * * *$ & 2,88 & $-0,76$ & $-1,27$ & 0,04 & 0,57 & 0,03 & 0,03 \\
\hline $\begin{array}{l}\text { Dummy para setor } \\
\text { intensivo em tecnologia }\end{array}$ & $0,56 * * *$ & 9,11 & $-0,25$ & $-0,41$ & $0,53 * * *$ & 7,84 & $0,56 * * *$ & 0,03 \\
\hline $\begin{array}{l}\text { Lambda (razão inversa } \\
\text { de Mills) }\end{array}$ & - & - & $-3,12 * * *$ & $-2,51$ & $-4,89 * * *$ & $-6,07$ & $-2,23 * * *$ & 0,26 \\
\hline Valor de F & 28 & 3,4 & 4,0 & & $24 \varepsilon$ & & 22 & \\
\hline Ajustado $\mathrm{R}^{2}$ & 0 , & & 0,3 & & 0,2 & & 0, & \\
\hline № de firmas & 2.4 & 85 & 57 & & 2.4 & & 2.4 & 85 \\
\hline
\end{tabular}

Fonte: FINEP (Financiadora de Estudos e Projetos), IBGE (Instituto Brasileiro de Geografia e Estatística): PINTEC (Pesquisa Industrial de Inovação Tecnológica) e PIA (Pesquisa Industrial Anual), SECEX/MDIC (Secretaria de Comércio Exterior/ Ministério do Desenvolvimento, Indústria e Comércio Exterior), Censo de Capital Estrangeiro/BACEN (Banco Central do Brasil), RAIS/MTE (Relação Anual de Informações Sociais/Ministério do Trabalho e Emprego).

Obs.: $\left(^{*}\right),\left({ }^{* *}\right),\left({ }^{* *}\right)$ : denotam variáveis significativas a $10 \%, 5 \%$ e $1 \%$ respectivamente. 
TABELA 14

Efeitos médios do tratamento (participação no ADTEN) sobre os gastos privados em P\&D das firmas a partir de diferentes especificações dos modelos - 2000

\begin{tabular}{|c|c|c|c|}
\hline \multirow[t]{2}{*}{ Modelo } & \multicolumn{3}{|c|}{ Impacto do ADTEN } \\
\hline & ATE & & Valor de $\mathrm{t}$ \\
\hline OLS & 0,36 & ns & 1,22 \\
\hline $\begin{array}{l}\text { Modelos de seleção (firmas beneficiárias } \\
\text { versus não-beneficiárias) - ATE1 }\end{array}$ & 0,33 & *** & 3,70 \\
\hline Modelos de seleção (para todas as firmas) - ATE2 & 0,25 & *** & 3,08 \\
\hline
\end{tabular}

Fonte: IBGE, Diretoria de Pesquisas, Coordenação de Indústria, Pesquisa Industrial de Inovação Tecnológica, 2000. Elaboração: IPEA-DISET a partir da transformação dos dados obtidos na fonte e com a incorporação de dados da PIA/ IBGE, SECEX/MDIC, CBE/BACEN, CEB/BACEN, ComprasNet/MPOG RAIS/MTE e FINEP.

Obs.: $\left(^{*}\right),\left({ }^{* *}\right),(* * *)$ denotam variáveis significativas a $10 \%, 5 \%$ e $1 \%$ respectivamente; (ns) denota impacto nãosignificativo.

que a dummy para empresa participante do ADTEN não apresentou significância estatística. Ou seja, se consideramos o modelo sem a correção para o viés de seleção, o resultado seria que o programa não tem efeitos sobre os esforços tecnológicos das firmas beneficiadas.

Entretanto, a significância da razão inversa de Mills mostra que o viés de seleção existe e que, portanto, precisa ser corrigido. Assim, calculamos o efeito médio do tratamento com base nas três equações dos modelos de seleção. A Tabela 14 sintetiza esses resultados e mostra que, ao contrário do encontrado no modelo de mínimos quadrados, o ADTEN tem impactos positivos e significativos sobre os gastos em P\&D das empresas beneficiadas.

Os resultados da Tabela 14 mostram que, de acordo com os modelos de seleção, as empresas beneficiadas pelo ADTEN gastaram em média, em 2000, entre $28 \%$ e $39 \%{ }^{32}$ a mais em P\&D do que as não-beneficiárias. Vale lembrar que esse impacto positivo foi calculado com base em um conjunto mais homogêneo de firmas: aquelas que já possuem gastos positivos em P\&D. Ou seja, existem evidências concretas de que o ADTEN estimula os gastos privados em P\&D, o que dá suporte à hipótese de adição.

32 Dado que a variável dependente se encontra na forma logarítmica, esse resultado foi obtido pela seguinte transformação: (exp (ATE) - 1)*100. 
Aplicamos o mesmo procedimento para outra variável dependente: a produtividade da empresa. Novamente, aqui, utilizamos a mesma equação de seleção expressa na Tabela A.3 (Anexo), com a diferença de que não utilizamos a amostra reduzida de firmas com gastos positivos em $\mathrm{P} \& \mathrm{D}$ mas sim a amostra completa (primeira coluna da tabela).

A especificação da equação de tratamento é a mesma utilizada para os gastos em P\&D e os resultados dos modelos de seleção e do modelo de mínimos quadrados são mostrados na Tabela 15. No caso da produtividade, entretanto, a razão inversa de Mills não foi significativa, o que torna a estimativa por mínimos quadrados adequada para avaliar a efetividade do programa. Nesse caso não será necessário, portanto, calcular o efeito médio do tratamento com base nos modelos de seleção.

A dummy para empresa participante do ADTEN no modelo de mínimos quadrados não foi estatisticamente significativa, embora tenha apresentado sinal positivo. Portanto, os resultados desse procedimento são consistentes com os obtidos por meio do teste de diferença de médias. Ou seja, embora em ambos os procedimentos os resultados possam sugerir um efeito positivo do ADTEN sobre a produtividade, em nenhum deles esse impacto é estatisticamente significativo.

\section{Síntese e considerações finais}

A avaliação de políticas públicas voltadas para o fomento de atividades de inovação tecnológica, principalmente aquelas direcionadas para fomentar P\&D nas empresas, são relativamente frequentes na literatura internacional dos países desenvolvidos. No entanto, para países em desenvolvimento como o Brasil, esses estudos são relativamente pouco frequentes e não há trabalhos econométricos publicados utilizando-se informações por firmas. Este trabalho procurou contribuir nesse sentido, ao avaliar o impacto do Programa de Apoio ao Desenvolvimento Tecnológico da Empresa Nacional (ADTEN) e de uma parte do Fundo Nacional de Desenvolvimento Científico e Tecnológico (FNDCT) - o chamado FNDCT cooperativo -, ambos administrados pela FINEP. Buscou-se verificar se esses programas influenciam positivamente o desempenho e o esforço tecnológico das firmas industriais brasileiras. Nesse sentido, este trabalho é inédito no seu conteúdo e procedimentos, pois também é a primeira vez que são utilizadas informaçôes por firmas para analisar o impacto de programas de apoio à inovação tecnológica no Brasil.

O primeiro aspecto da avaliação a ser ressaltado diz respeito à pequena abrangência dos dois programas. O FNDCT é um fundo destinado, essencialmente, para 
TABELA 15

Modelos de mínimos quadrados e de seleção para a variável dependente:

logaritmo da produtividade da empresa em 2000

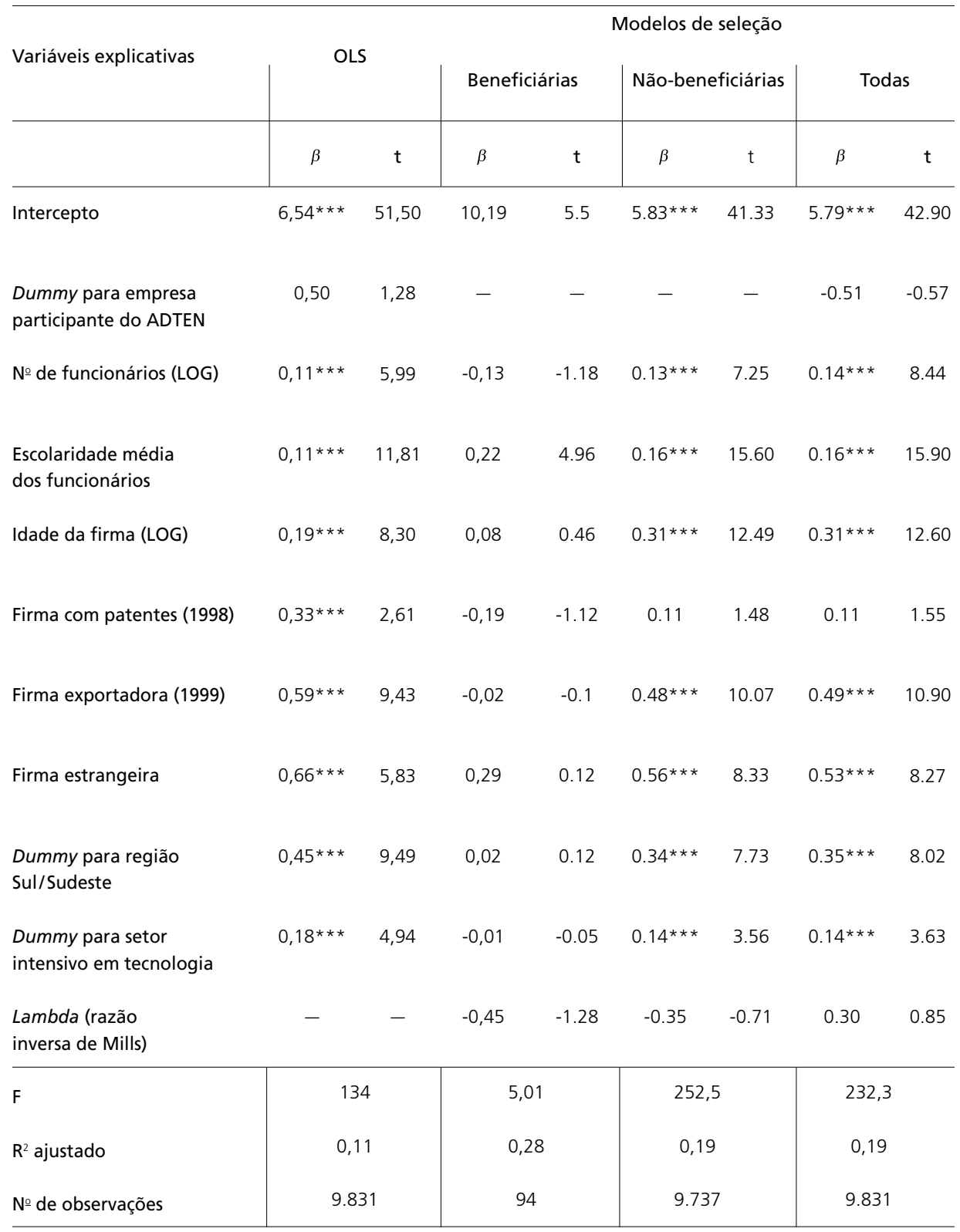

Fonte: IBGE, Diretoria de Pesquisas, Coordenação de Indústria, Pesquisa Industrial de Inovação Tecnológica, 2000. Elaboração: IPEA-DISET a partir da transformação dos dados obtidos na fonte e com a incorporação de dados da PIA/ IBGE, SECEX/MDIC, CBE/BACEN, CEB/BACEN, ComprasNet/MPOG RAIS/MTE e FINEP.

Obs.: $\left(^{*}\right),\left({ }^{* *}\right),(* * *)$ denotam variáveis significativas a $10 \%, 5 \%$ e $1 \%$ respectivamente. 
a pesquisa científica e tecnológica realizada no âmbito das universidades e centros de pesquisa. Nesse sentido, a participação do setor produtivo nos FNDCT é restrita ao que se chama de FNDCT cooperativo, que representa uma parcela muito pequena dos desembolsos totais do fundo. Com a criação dos fundos setoriais, a partir de 1999, as diretrizes do FNDCT passaram a privilegiar a pesquisa científica e tecnológica voltada aos interesses dos setores produtivos e a incentivar as parcerias entre universidade e empresas públicas ou privadas. Ainda assim, a participação das empresas continua bastante restrita, mesmo dentro do FNDCT cooperativo. Uma das razões para isso é a impossibilidade, pela legislação brasileira, de que fundos não-reembolsáveis sejam destinados a empresas privadas. Essa limitação, entretanto, começou a ser superada com a promulgação da Lei de Inovação, que, entre outras coisas, possibilita que o setor público subsidie atividades inovativas nas empresas brasileiras.

No mesmo sentido, o trabalho mostrou que o ADTEN tem alcance relativamente pequeno para as dimensões da indústria brasileira. $\mathrm{O}$ programa atende apenas $0,07 \%$ das firmas industriais brasileiras com mais de dez pessoas ocupadas e o volume de recursos que são emprestados para as empresas no âmbito do programa representam apenas 1,6\% e 3\% dos gastos das próprias empresas que são realizados em P\&D, em 2000 e 2003 respectivamente.

A despeito dessa pequena abrangência, os resultados obtidos nesse trabalho mostram que existem fortes evidências do impacto positivo desses programas sobre o desempenho e sobre os esforços tecnológicos das empresas por eles beneficiadas. Para chegar a essa conclusão, este artigo utilizou três diferentes métodos para avaliar o impacto dos dois programas sobre três diferentes aspectos do desempenho das firmas. Esses resultados estão sintetizados na Tabela 16.

Em relação aos impactos do programa sobre o desempenho econômico das firmas beneficiárias, particularmente sobre o crescimento e sobre a produtividade delas, os resultados foram bastante ambíguos. Muito embora não existam, evidentemente, impactos negativos, os impactos positivos nem sempre foram estatisticamente significativos. De fato, os resultados não apontam para um desempenho significativamente superior, em termos de produtividade, das firmas beneficiárias em relação às não-beneficiárias. Exceção a isso foram os impactos do FNDCT sobre a produtividade, avaliados a partir do Propensity Score Matching. Entretanto, esse foi o único, entre os três métodos, que gerou resultados positivos do programa sobre a produtividade das firmas. Esse resultado não é, contudo, pouco previsível. Aumentos de produtividade não são o foco dos programas e, para que fosse possível visualizar 
TABELA 16

Efeitos médios do tratamento (participação no ADTEN) sobre os gastos privados em P\&D das firmas a partir de diferentes especificações dos modelos - 2000

\begin{tabular}{|c|c|c|c|c|c|c|}
\hline & \multicolumn{3}{|c|}{ Impactos do ADTEN sobre } & \multicolumn{3}{|c|}{ Impactos do FNDCT sobre } \\
\hline & Crescimento & Produtividade & $\begin{array}{c}\text { Esforços } \\
\text { tecnológicos }\end{array}$ & Crescimento & Produtividade & $\begin{array}{c}\text { Esforços } \\
\text { tecnológicos }\end{array}$ \\
\hline PSM & & $\mathrm{ns}^{*}$ & + & & + & + \\
\hline $\begin{array}{l}\text { Modelos de } \\
\text { seleção }\end{array}$ & & & + & & & + \\
\hline OLS & & ns & & & ns & \\
\hline $\begin{array}{l}\text { PSM com } \\
\text { diferenças em } \\
\text { diferenças }\end{array}$ & + & ns & & ns & ns & \\
\hline
\end{tabular}

Fonte: elaboração própria

Obs.: (ns) denota impactos não-significativos; (ns*) significa que os resultados foram significativos em apenas uma especificação do teste, e não-significativos nas demais; (+) significa um impacto positivo e significativo do programa sobre a variável analisada. As partes com destaque significam que o método não foi aplicado para aquela variável.

impactos indiretos das atividades de P\&D sobre a produtividade, seria necessário muito mais tempo do que o disponível até o momento.

Em relação aos impactos sobre o crescimento, mais uma vez nos deparamos com a restrição do pequeno período de tempo disponível para a análise. Assim, o modelo de diferenças em diferenças mostrou impactos significativos do ADTEN sobre o crescimento das empresas enquanto evidenciou o fato do FNDCT não ter impactos sobre essa variável. Talvez o período menor de análise disponível para o FNDCT explique uma parte da divergência nos resultados dos dois programas sobre a produtividade.

Por fim, em relação aos esforços tecnológicos, os resultados fornecem elementos contundentes para a rejeição da hipótese de crowding out, ou seja, de que os recursos públicos aplicados em $\mathrm{P} \& \mathrm{D}$ nas empresas privadas poderiam deslocar os investimentos privados nessas atividades. Pelo contrário, o que os resultados mostram é que ambos os programas possuem efeitos positivos e significativos sobre os esforços tecnológicos privados das empresas industriais. Esse fato constitui um indício importante sobre a complementaridade dos recursos públicos e privados aplicados 
em P\&D. Podemos argumentar, com base na avaliação desses dois programas, que políticas públicas de financiamento ou de subsídios às atividades tecnológicas podem alavancar os esforços tecnológicos privados no país.

Esse resultado é de suma importância em um país onde apenas $13 \%$ ou $14 \%$ das empresas industriais inovadoras contam com algum tipo de suporte público para realizar a inovação e onde cerca $90 \%$ dos gastos em pesquisa são financiados com recursos próprios. Enquanto isso, nos países desenvolvidos, o percentual de firmas inovadoras que recebe apoio público para essa atividade é superior a $30 \%$ e o percentual dos gastos em P\&D financiados com recursos públicos ou de terceiros é bastante superior ao observado no Brasil. Os resultados são ainda mais relevantes se considerarmos que é necessário ampliar os esforços tecnológicos das empresas industriais brasileiras dos atuais $0,7 \%$ para níveis mais próximos daqueles observados em países com maior nível de desenvolvimento.

\section{Referências bibliográficas}

Aerts, K.; Czarnitzki, D. "Using innovation survey data to evaluate R\&D policy: the case of Belgium”, Discussion Paper, ZEW: Centre for European Economic Research, n.0555, 2004. Disponível em <http://opus.zbw-kiel.de/volltexte/2004/2193/pdf/dp0455. pdf $>$.

Arvanitis, S. Explaning Innovative Activity in Services Industries: Micro Data Evidence for Switzerland, 56, Swiss Institute for Bussines Cycle Research, Swiss Federal Institute for Technology, 2002.

Bastos, V.D. Fundos públicos para ciência e tecnologia, Rio de Janeiro: BNDES, 2003.

Blundell, R.; Costa Dias, M. "Evaluation methods for non-experimental data", Fiscal Studies, 21(4), p.427-468, 2000.

Busom, I. "An empirical evaluation of the effects of R\&D subsidies", Economics of Innovation and New Technology, 9(2), p.111-148, 2000.

De Negri, J.A. "Rendimentos crescentes de escala e o desempenho exportador das firmas industriais brasileiras", Tese de Doutorado, Brasília, UnB, 2003.

Greene, W.H. Econometric analysis, 4aㅡ. ed., Nova York: Prentice Hall, 2000. 
Guimarães, R. Os mecanismos de avaliação em ciência e tecnologia no Brasil, Rio de Janeiro: UERJ, 1993, Série Estudos em Saúde Coletiva, n.44.

Heckman, J. "Sample selection bias as a specification error", Econometrica, v.47, p.153-161, 1979.

Hussinger, K. "R\&D and subsidies at the firm level: an application of parametric and semiparametric two-step selection models", ZEW Discussion Paper, Mannheim: Centre for European Economic Research, n.03-63, 2003.

Jarmin, R.S. "Manufacturing extension and productivity dynamics", CES Working Paper, Washington, DC: U.S. Bureau of the Census, n.98-8, 1998.

Klette, T.J.; Griliches, Z.V.I. "Empirical patterns of firm growth and R\&D investment: a quality ladder model interpretation”, Economic Journal, 110, p.363-387, abr., 2000.

Meyer, B. "Natural and quasi-experiments in economics", Journal of Business and Economic Statistics, 13, p.151-161, 1995.

Naidin, L.C.; Figueiredo, C.M.P.; Magalhães, P. J. A implementação de projetos financiados pela FINEP com recursos do FNDCT, Rio de Janeiro: FINEP, 1977.

Pereira, A.S. Programa avançado em crédito, Rio de Janeiro: FINEP, 2002.

Wooldridge, J.M. Econometric analysis of cross section and panel data, Cambridge (MA): The Mit Press, 2002.

ENDEREÇO PARA CORRESPONDENCIA:

Fernanda De Negri-fernanda.denegri@ipea.gov.br

SBS - Quadra 1 - Bloco J - Edifício BNDES, 11 andar

70076-900 - Brasília (DF)

Tel: (61) 3315-5257

João Alberto De Negri-denegri@ipea.gov.br

SBS - Quadra 1 - Bloco J - Edifício BNDES, 11andar

70076-900 - Brasília (DF)

Tel: (61) 3315-5255

Mauro Borges Lemos - mbl@cedeplar.ufmg.br

Avenida Antônio Carlos, 6.627

31270-901 - Belo Horizonte (MG)

Tel: (31) 3409-7157 / 7086

Fax: (31) 3409-7203 


\section{Anexo}

\section{TABELA A.1}

Modelos probabilísticos para a participação da firma no FNDCT (PROBIT): amostra total, firmas inovadoras e firmas com gastos em P\&D - 2003

\begin{tabular}{|c|c|c|c|c|c|c|c|c|c|}
\hline \multirow{2}{*}{ Variáveis explicativas } & \multicolumn{3}{|c|}{ Amostra total } & \multicolumn{3}{|c|}{ Firmas inovadoras } & \multicolumn{3}{|c|}{$\begin{array}{c}\text { Firmas com } \\
\text { gastos em P\&D }\end{array}$} \\
\hline & Coef. & & DP & Coef. & & DP & Coef. & & DP \\
\hline Intercepto & $-4,73 * * *$ & & 0,42 & $-4,79 * * *$ & & 0,53 & $-4,49 * * *$ & & 0,60 \\
\hline № de funcionários (LOG) & $0,16 * * *$ & & 0,05 & $0,15 * * *$ & & 0,05 & $0,15^{* * *}$ & & 0,06 \\
\hline CR1 & $-0,28$ & & 0,19 & $-0,28$ & & 0,20 & $-0,25$ & & 0,22 \\
\hline CR2 & 0,19 & & 0,15 & $-0,31$ & & 0,22 & $-0,32$ & & 0,23 \\
\hline CR4 & $-0,11$ & & 0,16 & $-0,13$ & & 0,17 & $-0,30$ & & 0,19 \\
\hline CR5 & 0,04 & & 0,14 & 0,01 & & 0,16 & 0,00 & & 0,16 \\
\hline Idade da firma (LOG) & 0,06 & & 0,08 & 0,08 & & 0,10 & 0,10 & & 0,11 \\
\hline Market share & $2,03 * * *$ & & 0,77 & $2,13^{* *}$ & & 0,86 & $2,07 * *$ & & 0,88 \\
\hline Empresa estrangeira & $-0,62 * * *$ & & 0,16 & $-0,74 * * *$ & & 0,19 & $-0,75^{\star * *}$ & & 0,20 \\
\hline $\begin{array}{l}\text { Empresa exportadora } \\
\text { (defasada) }\end{array}$ & $0,69 * * *$ & & 0,14 & $0,46 * * *$ & & 0,16 & $0,43 * *$ & & 0,17 \\
\hline $\begin{array}{l}\text { Empresa com atividades } \\
\text { contínuas de P\&D }\end{array}$ & $0,71 * * *$ & & 0,11 & $0,74 * * *$ & & 0,13 & $0,40 * *$ & & 0,16 \\
\hline $\begin{array}{l}\text { Dummy para setor } \\
\text { intensivo em tecnologia }\end{array}$ & $0,36 * * *$ & & 0,10 & $0,50 * * *$ & & 0,13 & $0,54 * * *$ & & 0,14 \\
\hline Dummy para região & & & & & & & & & \\
\hline Sul ou Sudeste & 0,04 & & 0,12 & 0,22 & & 0,16 & 0,18 & & 0,17 \\
\hline $\begin{array}{l}\text { Beneficiárias } \\
\text { (amostra/população) }\end{array}$ & 49 & / & 69 & 41 & l & 56 & 40 & / & 53 \\
\hline $\begin{array}{l}\text { Não-beneficiárias } \\
\text { (amostra/população) }\end{array}$ & 10.237 & l & 81.371 & 4.725 & l & 29.612 & 1.751 & I & 5.557 \\
\hline Log likelihood & $-346,5$ & & & $-256,97$ & & & $-231,87$ & & \\
\hline Pseudo $\mathrm{R}^{2}$ & 0,39 & & & 0,38 & & & 0,26 & & \\
\hline
\end{tabular}

Fonte: IBGE, Diretoria de Pesquisas, Coordenação de Indústria, Pesquisa Industrial de Inovação Tecnológica, 2000. Elaboração: IPEA-DISET a partir da transformação dos dados obtidos na fonte e com a incorporação de dados da PIA/ IBGE, SECEX/MDIC, CBE/BACEN, CEB/BACEN, ComprasNet/MPOG RAIS/MTE e FINEP.

Obs.: $\left(^{*}\right),\left({ }^{* *}\right),\left({ }^{* *}\right)$ denotam variáveis significativas a $10 \%, 5 \%$ e $1 \%$ respectivamente; (ns) denota variável nãosignificativa. $\mathrm{O}$ número de firmas $\mathrm{n}$ corresponde à amostra e $\mathrm{N}$ é o número de firmas na população (utilizando-se o fator de ponderação). 
TABELA A.2

Modelo probabilístico para a participação no FNDCT em 1999

(PROBIT para firmas com mais de 30 pessoas ocupadas)

\begin{tabular}{|c|c|c|}
\hline \multirow[b]{2}{*}{ Variáveis } & \multicolumn{2}{|c|}{$\begin{array}{l}\text { Todas as firmas com mais } \\
\text { de } 30 \text { pessoas ocupadas }\end{array}$} \\
\hline & Coef. & Desvio \\
\hline Intercepto & $3,99 * * *$ & 0,45 \\
\hline № de funcionários (LOG) & $0,25 * * *$ & 0,06 \\
\hline CR1 & $-0,07$ & 0,22 \\
\hline CR2 & $-0,43^{*}$ & 0,26 \\
\hline CR4 & $-0,04$ & 0,15 \\
\hline CR5 & $-0,07$ & 0,15 \\
\hline Idade da firma (LOG) & $-0,05$ & 0,08 \\
\hline Market share & $1,69 * *$ & 0,65 \\
\hline Firma estrangeira & $-0,39 * *$ & 0,17 \\
\hline Firma exportadora (defasada) & $0,41 * * *$ & 0,14 \\
\hline Firma com patentes (defasada) & 0,23 & 0,14 \\
\hline Dummy para setor intensivo em tecnologia & $0,32 * * *$ & 0,11 \\
\hline Dummy para região Sul ou Sudeste & $-0,03$ & 0,13 \\
\hline
\end{tabular}

Beneficiárias ( $\mathrm{n}$ )

48

Não-beneficiárias ( $n$ )

15.418

Log likelihood

$-262,84$

Pseudo $\mathrm{R}^{2}$

0,19

Fonte: IBGE, Diretoria de Pesquisas, Coordenação de Indústria, Pesquisa Industrial de Inovação Tecnológica, 2000. Elaboração: IPEA-DISET a partir da transformação dos dados obtidos na fonte e com a incorporação de dados da PIA/ IBGE, SECEX/MDIC, CBE/BACEN, CEB/BACEN, ComprasNet/MPOG RAIS/MTE e FINEP.

Obs.: $\left(^{*}\right),\left(^{* *}\right),\left({ }^{* *}\right)$ denotam variáveis significativas a $10 \%, 5 \%$ e $1 \%$ respectivamente. 
TABELA A.3

Modelos probabilísticos para a participação da firma no FNDCT (PROBIT): amostra total, firmas inovadoras e firmas com gastos em P\&D - 2003

\begin{tabular}{|c|c|c|c|c|c|c|c|c|c|}
\hline \multirow{2}{*}{ Variáveis explicativas } & \multicolumn{3}{|c|}{ Amostra total } & \multicolumn{3}{|c|}{ Firmas inovadoras } & \multicolumn{3}{|c|}{$\begin{array}{l}\text { Firmas com } \\
\text { gastos em P\&D }\end{array}$} \\
\hline & Coef. & & Desvio & Coef. & & Desvio & Coef. & & Desvio \\
\hline Intercepto & $-4,19 * * *$ & & 0,22 & $-3,72 * * *$ & & 0,25 & $-3,85^{* * *}$ & & 0,33 \\
\hline № de funcionários (LOG) & $0,23 * * *$ & & 0,03 & $0,20 * * *$ & & 0,04 & $0,19 * * *$ & & 0,05 \\
\hline CR1 & $-0,44 * * *$ & & 0,11 & $-0,39 * * *$ & & 0,13 & $-0,46 * * *$ & & 0,17 \\
\hline CR2 & $-0,49 * * *$ & & 0,15 & $-0,60 * * *$ & & 0,18 & $-0,95^{* * *}$ & & 0,31 \\
\hline CR4 & 0,13 & & 0,09 & 0,07 & & 0,11 & 0,05 & & 0,13 \\
\hline CR5 & 0,10 & & 0,10 & $-0,02$ & & 0,12 & $-0,05$ & & 0,14 \\
\hline Idade da firma (LOG) & $0,09 * *$ & & 0,04 & 0,01 & & 0,05 & $0,13 * *$ & & 0,06 \\
\hline Market share & 0,29 & & 0,69 & 0,56 & & 0,71 & 0,60 & & 0,74 \\
\hline Empresa estrangeira & $-0,51 * * *$ & & 0,12 & $-0,60 * * *$ & & 0,14 & $-0,66^{* * *}$ & & 0,17 \\
\hline $\begin{array}{l}\text { Empresa exportadora } \\
\text { em } 1998 \text { (defasada) }\end{array}$ & $0,39 * * *$ & & 0,08 & $0,50 * * *$ & & 0,09 & $0,28 * *$ & & 0,12 \\
\hline $\begin{array}{l}\text { Empresa com atividades } \\
\text { contínuas de P\&D }\end{array}$ & $0,29 * * *$ & & 0,08 & $0,20 * * *$ & & 0,09 & $0,24^{* *}$ & & 0,11 \\
\hline $\begin{array}{l}\text { Setor intensivo em } \\
\text { tecnologia }\end{array}$ & $0,20 * * *$ & & 0,07 & $0,22 * * *$ & & 0,08 & $0,19 *$ & & 0,10 \\
\hline Região Sul ou Sudeste & 0,09 & & 0,08 & 0,11 & & 0,10 & 0,06 & & 0,12 \\
\hline $\begin{array}{l}\text { Beneficiárias } \\
\text { (amostra/população) }\end{array}$ & 94 & / & 135 & 77 & / & 110 & 58 & / & 76 \\
\hline $\begin{array}{l}\text { Não-beneficiárias } \\
\text { (amostra/população) }\end{array}$ & 9.884 & / & 69.463 & 5.214 & / & 25.006 & 2.600 & I & 8.138 \\
\hline Log likelihood & $-703,5$ & & & $-544,9$ & & & $-340,6$ & & \\
\hline Pseudo $\mathrm{R}^{2}$ & 0,3 & & & 0,25 & & & 0,24 & & \\
\hline
\end{tabular}

Fonte: IBGE, Diretoria de Pesquisas, Coordenação de Indústria, Pesquisa Industrial de Inovação Tecnológica, 2000. Elaboração: IPEA-DISET a partir da transformação dos dados obtidos na fonte e com a incorporação de dados da PIA/ IBGE, SECEX/MDIC, CBE/BACEN, CEB/BACEN, ComprasNet/MPOG RAIS/MTE e FINEP.

Obs.: $\left({ }^{*}\right),\left({ }^{* *}\right),\left({ }^{* *}\right)$ denotam variáveis significativas a $10 \%, 5 \%$ e $1 \%$ respectivamente; (ns) denota testes nãosignificativos. 
TABELA A.4

Modelos probabilísticos para o fato de a firma participar do ADTEN: 1996 (PROBIT para firmas com mais de 30 funcionários)

\begin{tabular}{|c|c|c|}
\hline \multirow{2}{*}{ Variáveis } & \multicolumn{2}{|c|}{$\begin{array}{l}\text { Todas as firmas com mais } \\
\text { de } 30 \text { pessoas ocupadas }\end{array}$} \\
\hline & Coef. & Desvio \\
\hline Intercepto & $-3,97 * * *$ & 0,35 \\
\hline № de funcionários (LOG) & $0,22 * * *$ & 0,04 \\
\hline CR1 & $-0,23^{*}$ & 0,13 \\
\hline CR2 & $-0,13$ & 0,13 \\
\hline CR4 & 0,07 & 0,11 \\
\hline CR5 & $-0,02$ & 0,11 \\
\hline Idade da firma (LOG) & 0,03 & 0,07 \\
\hline Market share & 0,49 & 0,61 \\
\hline Empresa estrangeira & $-0,47 * * *$ & 0,15 \\
\hline Empresa exportadora em 1995 & $0,39 * * *$ & 0,09 \\
\hline Empresa com patentes em 1995 & $0,27 * *$ & 0,13 \\
\hline Dummy para setor intensivo em tecnologia & $0,23 * * *$ & 0,08 \\
\hline Dummy para região Sul ou Sudeste & $0,16^{*}$ & 0,09 \\
\hline Beneficiárias (n) & & \\
\hline Não-beneficiárias (n) & & \\
\hline Log likelihood & & \\
\hline $\mathrm{R}^{2}$ & & \\
\hline
\end{tabular}

Fonte: IBGE, Diretoria de Pesquisas, Coordenação de Indústria, Pesquisa Industrial de Inovação Tecnológica, 2000. Elaboração: IPEA-DISET a partir da transformação dos dados obtidos na fonte e com a incorporação de dados da PIA/ IBGE, SECEX/MDIC, CBE/BACEN, CEB/BACEN, ComprasNet/MPOG RAIS/MTE e FINEP.

Obs.: $\left(^{*}\right),\left({ }^{* *}\right),\left({ }^{* *}\right)$ denotam variáveis significativas a $10 \%, 5 \%$ e $1 \%$ respectivamente. 